\title{
The Mitogen-Activated Protein Kinase BcSak1 of Botrytis cinerea Is Required for Pathogenic Development and Has Broad Regulatory Functions Beyond Stress Response
}

\author{
Jens Heller, ${ }^{1}$ Nadja Ruhnke, ${ }^{1}$ José Juan Espino, ${ }^{1}$ Michelli Massaroli, ${ }^{2}$ Isidro Gonzalez Collado, ${ }^{2}$ and \\ Paul Tudzynski ${ }^{1}$ \\ ${ }^{1}$ Institut fuer Biologie und Biotechnologie der Pflanzen, Westf. Wilhelms-Universitaet, Hindenburgplatz 55, D-48143 Muenster, \\ Germany; ${ }^{2}$ Departamento de Química Orgánica, Facultad de Ciencias, Universidad de Cádiz, 11510 Puerto Real, Spain
}

Submitted 22 November 2011. Accepted 13 February 2012.

\begin{abstract}
The mitogen-activated protein kinase (MAPK) BcSak1 of Botrytis cinerea is activated upon exposure to $\mathrm{H}_{2} \mathrm{O}_{2}$ and, hence, might be involved in coping with oxidative stress during infection. However, beside osmotic and oxidative stress sensitivity, $\Delta$ bcsak 1 mutants have a pleiotropic phenotype, as they do not produce conidia and are unable to penetrate unwounded host tissue. In this study, the role of BcSak1 was investigated in the stress response and during infection of French beans by Botrytis cinerea. Using a macroarray approach, it was shown that BcSak1 is only marginally involved in the specific oxidative stress response. In fact, the induction of several genes after oxidative stress treatment is BcSak1-dependent, but most of these genes are also induced under conditions of osmotic stress. The majority of genes regulated by BcSak1 are not involved in the stress response at all. Using a translational fusion of BcSak1 to green fluorescent protein, it was shown clearly that the localization of this MAPK depends on the type of stress being applied; it associates rapidly to the nucleus only under osmotic stress. Therefore, a model is proposed in which BcSak1 acts in the cytosol by activation of one or more transcription factors under oxidative stress and, at the same time, it reacts to osmotic stress by migrating to the nucleus. Interestingly, the MAPK is also involved in the regulation of secondary metabolism, as the major phytotoxins secreted by this fungus are reduced in the $\Delta$ bcsak 1 deletion mutant. Experiments done in planta underlined the essential role of BcSak1 in the early stages of infection, when it translocates to the nucleus and then changes to cytosolic distribution during hyphal growth within the tissue.
\end{abstract}

Botrytis cinerea Pers.:Fr. [teleomorph Botryotinia fuckeliana (de Bary) Whetzel] is a necrotrophic plant pathogen that causes gray mold disease in more than 200 crop species, leading to serious pre- and postharvest losses worldwide (Williamson et al. 2007). The fungus is capable of infecting such a wide host range, indicating it evolved a flexible infection strategy, including manifold tools for penetrating and colonizing its host tis-

Corresponding author: Paul Tudzynski; E-mail: tudzyns@uni-muenster.de

* The $\boldsymbol{e}$-Xtra logo stands for "electronic extra" and indicates that seven supplementary figures, three supplementary tables, and a supplementary movie are published online. sues. Therefore, it produces different cell wall-degrading enzymes and nonspecific phytotoxic metabolites, such as botrydial and botcinolides (Brito et al. 2006; Siewers et al. 2005; Ten Have et al. 1998; Valette-Collet et al. 2003). During the infection process, host cells at the infection site are killed rapidly and the fungus grows as a necrotroph, building necrotic lesions until, finally, it macerates the whole plant tissue and generates new conidia.

A first broad and unspecific defense reaction of plants against invading pathogens is the oxidative burst, a process in which the plants produce large quantities of reactive oxygen species (ROS) around the infection site. Being highly reactive molecules, ROS can interact with macromolecules like DNA, proteins, or lipids and destroy them. However, ROS are also used by cells as second messengers that transmit different intracellular signals (Lara-Ortíz et al. 2003). Accordingly, the ROS built during the oxidative burst serve different purposes-they are aimed to evoke oxidative stress to harm the pathogen directly, they serve as messenger molecules within the plant, and they are aimed to kill the plant cells surrounding the infection site and, thus, restrict biotrophic pathogens in the hypersensitive response (HR) (Talarczyk and Hennig 2001).

It has been shown previously that $B$. cinerea, as a necrotrophic pathogen, induces a significant oxidative burst in all analyzed host tissues and, notably, does not restrict it during infection (Lyon et al. 2007). In fact, B. cinerea even seems to enhance the oxidative burst by producing its own ROS (Tenberge et al. 2002; Tiedemann 1997). Accordingly, in contrast to biotrophic pathogens, $B$. cinerea is not markedly delayed by the oxidative burst and the HR of plants but, rather, benefits from these defense reactions to achieve full virulence (Govrin and Levine 2000). To elucidate if the plant's oxidative burst causes oxidative stress in $B$. cinerea during infection, components of the fungal oxidative stress response system must be identified and characterized.

While the superoxide dismutase BcSod1 is an important single virulence factor (Rolke et al. 2004), disruption of a gene encoding for an extracellular catalase (bccat2) had no effect on virulence (Schouten et al. 2002). In addition, it was shown recently that the transcription factor Bap1, which is the major transcriptional regulator of the $\mathrm{H}_{2} \mathrm{O}_{2}$-mediated oxidative stress response in axenic culture, is not a virulence factor of $B$. cinerea (Temme and Tudzynski 2009). Therefore, it was proposed that ROS produced by the plant do not play a major role for the interaction between $B$. cinerea and its hosts. Nevertheless, there 
are still many other signaling networks involved in stress signal transduction. Among them the mitogen-activated protein kinase (MAPK) signaling pathway is particularly important.

MAPK are a family of highly conserved serine and threonine kinases that coordinate the adaptation of cellular functions to changing environmental conditions and thereby regulate growth and differentiation processes in eukaryotic cells (Schaeffer and Weber 1999). After activation, the MAPK activate the transcription machinery by phosphorylating substrates like transcription factors, resulting in modulation of protein activity and altered gene expression (de Nadal and Posas 2009). MAPK that respond to environmental stresses are called stress-activated protein kinases (SAPK). One of those is Hog1 from the eukaryotic model organism Saccharomyces cerevisiae. It specifically responds to an increase in extracellular osmolarity and is required for cell adaptation to osmotic stress (Brewster et al. 1993). Besides Hog1, S. cerevisiae possesses four other MAPK with diverse and specific functions (Gustin et al. 1998).

In contrast to yeast, most filamentous fungi possess only three MAPK cascades (Xu 2000). The corresponding proteins show homology to the MAPK involved in the pheromone response pathway (Fus3/Kss1), the cell integrity pathway (Slt2), and the high osmolarity glycerol pathway (Hog) of yeast. As shown for Aspergillus fumigatus, Bipolaris oryzae, Magnaporthe grisea, and Neurospora crassa, an essential role of Hog1 homologs, especially for osmoregulation but also for the oxidative stress response, in filamentous fungi seems to be conserved (Dixon et al. 1999; Du et al. 2006; Moriwaki et al. 2006; Zhang et al. 2002). An exception is Aspergillus nidulans, in which the role of SakA in adaptation to osmotic changes is of minor importance, even though the protein is activated under conditions of osmotic stress (Kawasaki et al. 2002).

In $B$. cinerea, all MAPK-encoding genes have been functionally characterized by gene replacements, and it was shown that all of them are required for pathogenicity. The Fus3/Kss1 homolog MAPK Bmp1 is essential for pathogenicity, due to its role in differentiation of appressoria-like structures and germination on hydrophobic surfaces (Doehlemann et al. 2006; Zheng et al. 2000). The Slt2 homolog MAPK Bmp3 is essential for full virulence, since it is involved in sporulation, surface sensing of germ tubes, host penetration, and lesion formation (Rui and Hahn 2007). In contrast to other fungal Hog1 homo$\operatorname{logs}, \mathrm{BcSak} 1$ of $B$. cinerea is essential for differentiation of conidia and penetration structures. The impact on virulence might result from its impaired oxidative stress tolerance, as the gene bcsakl is up-regulated and the protein BcSak1 is acti-

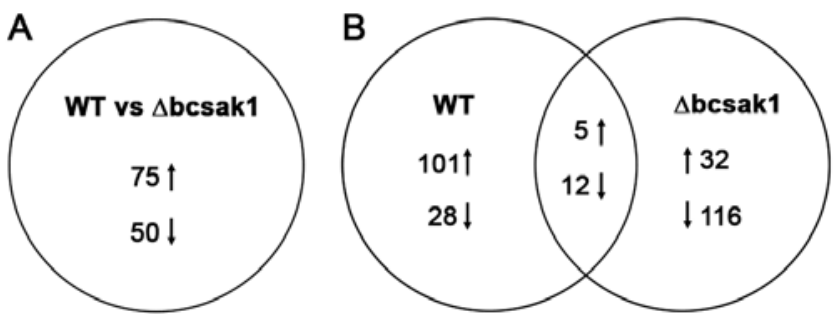

Fig. 1. Comparison of the transcriptional profiles of Botrytis cinerea wild type (WT) and the $\Delta$ bcsakl deletion mutant. Strains were cultivated in defined minimal medium before oxidative stress was induced using 10 $\mathrm{mM} \mathrm{H}_{2} \mathrm{O}_{2}$. A, The number of genes regulated differentially in $\Delta$ bcsak1 compared with the WT without applying any stress. B, Number of genes regulated differentially in WT and $\Delta$ bcsak1, respectively, after applying oxidative stress. Numbers covered by both circles indicate genes that are regulated the same in both strains. $\uparrow$ indicates induced and $\downarrow$ indicates repressed. vated during the oxidative stress response induced by $\mathrm{H}_{2} \mathrm{O}_{2}$ (Liu et al. 2008; Segmüller et al. 2007).

In this study, the role of BcSak1 in the stress response of Botrytis cinerea was further investigated. Using a macroarray approach, it is shown that, in B. cinerea, the induction of several genes after oxidative stress treatment is BcSak1-dependent. However, hardly any of these genes are induced in an oxidative stress-specific manner because they are also induced under osmotic stress. Strikingly, as shown by functional categorization, the majority of those genes are not even involved in the actual stress response. Using a translational fusion of BcSak1 to green fluorescent protein (GFP), it is shown that, although being involved in the regulation of the response to several stresses, the localization of this SAPK depends on the type of stress being applied. Therefore, a model is proposed in which BcSak1 acts via cytosolic activation of transcription factors in oxidative stress response, while reaction to osmotic stress requires nuclear localization. Our studies in planta show that, during early stages of infection, the SAPK is associated with the nucleus, but then, it becomes distributed in the cytosol during colonization of host tissue, as is the case during saprotrophic growth. These data strongly suggest that the essential role of BcSak1 in early infection stages is not due to its involvement in the oxidative stress response.

\section{RESULTS}

\section{The SAPK BcSak1 controls a large set of genes at transcriptional level.}

The MAPK BcSak1 is a Hog-type stress-activated MAPK. However, besides activating the stress response, it seems to be important for vegetative differentiation, as the deletion mutant of bcsakl develops neither conidiophores nor mature conidia (Segmüller et al. 2007). Genes that are responsible for this striking phenotype have not yet been identified. To analyze whether the transcriptional profile of the deletion mutant $\Delta$ bcsak1 differs from the wild-type strain (WT) under standard (i.e., nonstress) conditions, the transcriptomes of both strains were compared with each other, using a macroarray approach after cultivation in Czapek-Dox (CD) medium without further treatment. Indeed, the transcriptional profiles of both strains differed clearly (Fig. 1A). Compared with the WT, 75 genes in strain $\Delta$ bcsak1 were up-regulated and 50 genes were downregulated under these nonstress conditions. After categorizing the genes according to the Munich Information Center for Protein Sequences (MIPS) functional catalog database (Ruepp et al. 2004), it turned out that a considerable proportion (about $20 \%$ ) of genes that are induced in the deletion mutant could be assigned to the stress response (Supplementary Fig. S1), but most of the upregulated genes grouped to functions in regulation and differentiation (20\%) or metabolism (24\%). Within the genes that were repressed in the deletion mutant, the stress response played a minor role; only $4 \%$ could be assigned to this group. However, the proportion of genes identified to be reduced in the mutant that are involved in regulation and differentiation $(22 \%)$ or in metabolism $(20 \%)$ resembles that of the induced genes. These data (summarized in Supplementary Table S1) indicate that, under standard conditions, BcSak1 controls a large set of genes not directly involved in stress response and that its role is, rather, a repression of stress-related genes under nonstress conditions.

\section{Oxidative stress treatment induces \\ a different transcriptional response in $\Delta$ bcsak1 and WT.}

It was shown in previous studies that the deletion mutant $\Delta$ bcsak1 is sensitive to $\mathrm{H}_{2} \mathrm{O}_{2}$ and is unable to infect unwounded plant tissue (Segmüller et al. 2007). Since plants react with an 
oxidative burst to a pathogen attack, a direct correlation between both observed phenotypes was postulated. However, only a few known oxidative stress response genes were tested for their transcriptional dependency on BcSak1. To identify more genes whose induction after $\mathrm{H}_{2} \mathrm{O}_{2}$ treatment depends on $\mathrm{BcSak} 1$, a macroarray approach was performed, in which the transcriptional profiles of WT strain B05.10 and deletion mutant $\Delta$ bcsak1 were compared after $\mathrm{H}_{2} \mathrm{O}_{2}$ treatment. Therefore, axenic cultures were exposed to oxidative stress mediated by $10 \mathrm{mM}$ $\mathrm{H}_{2} \mathrm{O}_{2}$ for $30 \mathrm{~min}$. It was found that the transcriptional response of the deletion mutant was clearly affected (Fig. 1 B). The regulation of only 17 genes was found to be the same in WT and deletion mutant in response to oxidative stress treatment (five genes induced and 12 genes repressed). In contrast, expression of 129 genes was affected only in the WT after $\mathrm{H}_{2} \mathrm{O}_{2}$ treatment (101 genes induced and 28 genes repressed), and 148 genes were affected only in the deletion mutant (32 genes induced and 116 genes repressed). These findings indicate that the mutant is unable to react properly to the stress situation applied.
Regarding the strong phenotype of the mutant on oxidative stress media, BcSak1-dependent genes induced in the WT after $\mathrm{H}_{2} \mathrm{O}_{2}$ treatment seem to be of major interest. However, a closer examination of those genes, using the MIPS functional catalog database (Ruepp et al. 2004), indicated that most of them grouped to general metabolism $(32 \%)$ rather than being directly involved in the oxidative stress response or, at least, in the general stress response (12\%). Therefore, BcSak1 does not seem to predominantly control the "classical" oxidative stress response genes but, instead, seems to be important to redirect basic metabolic processes so that the fungus can adapt to the oxidative stress situation.

Besides BcSak1, another MAPK mutant of $B$. cinerea ( $\Delta$ bmp3) shows retarded growth rates on media containing $\mathrm{H}_{2} \mathrm{O}_{2}$ (Supplementary Fig. S2). In addition, it controls the genes encoding for the catalytic subunits of the $\mathrm{O}_{2}^{-}$-producing NADPH oxidase complex bcnoxA and bcnoxB at the transcriptional level (Fig. 2C, induction of bcnoxA, repression of bcnoxB) (Segmüller et al. 2008). Bmp3 is the MAPK homologous to yeast Slt2 and, in B. cinerea, it is involved in sporula-

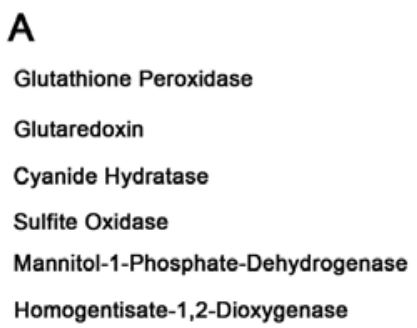

B

Hypothetical Protein
Mannitol Dehydrogenase BcMtdh
Methyltransferase CMCJ
GST dependent Formaldehyde Dehydrogenase
Pil1
BcReg1
Family A1 Protease

C

Peroxiredoxin

SRY-BOX 5

Pyruvate Decarboxylase

Cell Wall Glucanase

Endopolygalacturonase

HSP 70-2

NoxB

NoxA

Hypothetical Protein

rDNA
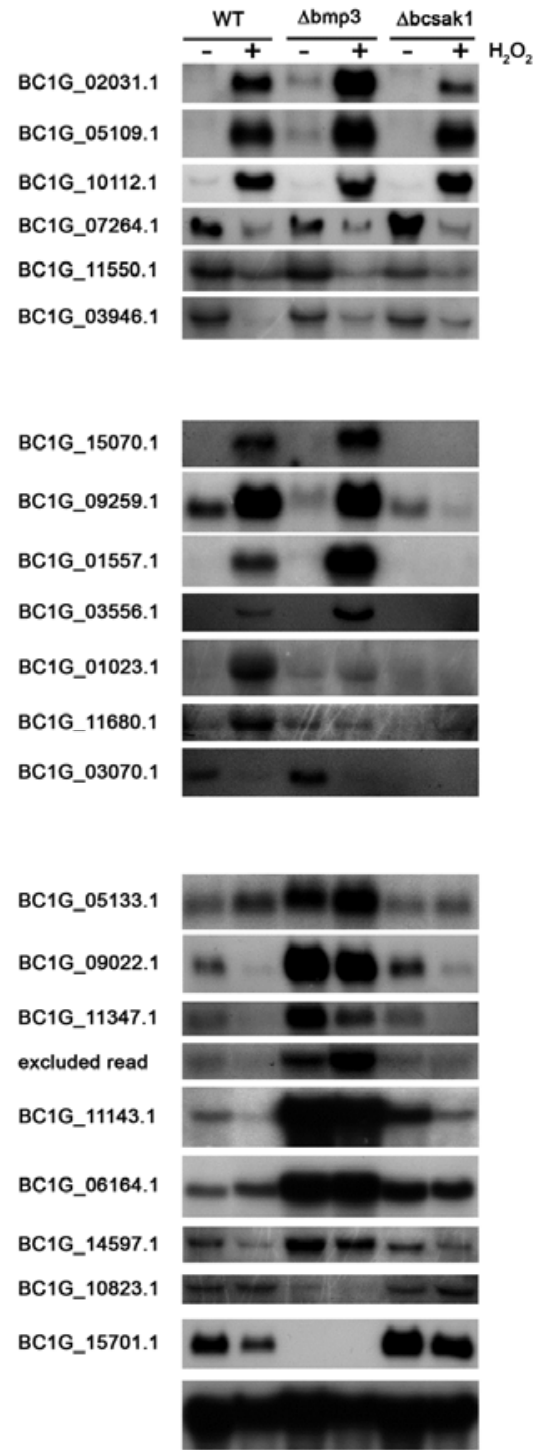

Fig. 2. Expression analysis for verification of macroarray results of selected genes that appeared to be regulated differentially in an oxidative stress or mitogen-activated protein kinase (MAPK)-dependent manner (BcSak1/BMP3). Expression of the corresponding genes was analyzed in the wild-type (WT) B05.10 and in the two MAPK mutants $\Delta$ bcsak1 and $\Delta \mathrm{bmp3}$. A, Genes regulated differentially after oxidative stress treatment independently of either MAPK. B, BcSak1-dependent genes that are regulated differentially after oxidative stress treatment. C, Bmp3-dependent genes. Cultivation under nonstress conditions was performed in Czapek-Dox medium (-). Oxidative stress was induced by adding $10 \mathrm{mM} \mathrm{H}_{2} \mathrm{O}_{2}(+)$ for half an hour. rDNA was used as loading control. 
tion, surface sensing of germ tubes, host penetration, and lesion formation (Rui and Hahn 2007). A macroarray approach similar to that of the $\Delta$ bcsak1 mutant was performed using the $\Delta$ bmp3 mutant, but the analysis showed that Bmp3 has only a minor role in the regulation of the oxidative stress response (summarized in Supplementary Table S2). However, in Northern blot experiments, performed to verify the results of the $\Delta$ bcsak1 macroarrays, the $\Delta \mathrm{bmp} 3$ mutant was included. The results of these Northern blot experiments confirmed the macroarray results for $50 \%$ of the tested genes while, for $25 \%$ of the tested genes, the expression signals were too weak to draw any conclusion. According to the macroarray analysis, only a small number of classical oxidative stress response genes were regulated by BcSak1. Therefore, in addition to them, a subset of other $\mathrm{H}_{2} \mathrm{O}_{2}$-induced genes that are BcSak1-dependent was chosen for verification.

The Northern blot experiments proved that typical oxidative stress response genes like a glutathione peroxidase (BC1G 02031.1) or a glutaredoxin (BC1G_05109.1) were induced after $\mathrm{H}_{2} \mathrm{O}_{2}$ treatment in $\mathrm{B}$. cinerea and that this induction is independent of both MAPK (Fig. 2A). Other genes, such as the cyanide hydratase $\left(B C 1 G_{-} 10112.1\right)$, which is involved in detoxification of hydrogen cyanide, a compound produced during fungal infection of cyanogenic plants, showed the same expression pattern. Otherwise, there were genes like the sulfite oxidase (BC1G_07264.1), the mannitol-1-phosphate-dehydrogenase (BC1G_11550.1), or the homogentisate-1,2-dioxygenase (BC1G_03946.1), that were all repressed after $\mathrm{H}_{2} \mathrm{O}_{2}$ treatment independently of both MAPK.

However, there were other genes whose induction after $\mathrm{H}_{2} \mathrm{O}_{2}$ treatment is BcSak1 dependent (Fig. 2B). The analysis showed that, among them, there is a mannitol dehydrogenase $\left(\mathrm{BC}_{1} \mathrm{G}_{-}\right.$ 09259.1), a methyltransferase (BC1G_01557.1), a GST-dependent formaldehyde dehydrogenase (BC1G_03556.1), and a hypothetical protein (BC1G_15070.1). The exact function of those genes during oxidative stress treatment is not clear. Genes such as pill (BC1G_01023.1) and bcreg1 (BC1G_11680.1) were also induced after $\overline{\mathrm{H}}_{2} \mathrm{O}_{2}$ treatment, but interestingly, the induction of these genes depended on both MAPK, BcSak1 and Bmp3. Apart from this result, no $\mathrm{H}_{2} \mathrm{O}_{2}$-inducible gene that specifically depends on Bmp3 was identified. Indeed, many genes have been identified that are deregulated in the $\Delta$ bmp 3 deletion mutant, even under standard conditions (Fig. 2C). Among them, there are stress response genes like a peroxiredoxin (BC1G_05133.1) or hsp70-2 (BC1G_06164.1) but, also, genes involved in metabolism, like a pyruvate decarboxylase $\left(\mathrm{BC} 1 \mathrm{G} \_11347.1\right)$ or an endopolygalacturonase (BC1G_11143.1).

\section{BcSak1-controlled genes are induced in response to several stresses instead of being specific for oxidative stress.}

The $\Delta$ bcsak1 deletion mutant is not only sensitive to oxidative stress but to several stresses (Segmüller et al. 2007). To analyze if genes controlled by BcSak1 are oxidative stress-specific, a selection of genes induced with $\mathrm{H}_{2} \mathrm{O}_{2}$ in the WT were tested for their induction after osmotic stress treatment $(1 \mathrm{M} \mathrm{NaCl}$, $30 \mathrm{~min}$ ) (Fig. 3). As shown for the stress protein $d d r 48$ (BC1G_ 10423.1), the stress protein rci (BC1G_12557.1), the opsin bop1 (BC1G_02456.1), the chitinase 2 (BC1G_12279.1), and a hypothetical protein (BC1G_12228.1), most BcSak1-dependent genes that are induced after $\mathrm{H}_{2} \mathrm{O}_{2}$ treatment in the WT are also induced in response to osmotic stress. The only exception identified so far is the gene bccat2, whose induction is oxidetive stress-specific (Fig. 4). In the $\Delta$ bmp3 mutant, the expression pattern of the stress responsive genes tested resembled that of the WT. Only the chitinase 2 , whose strong induction under both stress conditions is missing in the $\Delta$ bmp 3 mutant as well as in the $\Delta$ bcsak1 mutant, depends on both MAPK.

\section{Catalases are deregulated in $\Delta$ bcsak 1 deletion mutant.}

Catalases are important enzymes involved in the scavenging of $\mathrm{H}_{2} \mathrm{O}_{2}$. Therefore the expression of seven putative catalaseencoding genes of $B$. cinerea was analyzed regarding their dependency on BcSak1.

In Northern blot experiments, transcripts could be detected only for four catalases under the conditions tested (Supplementary Fig. S3). Therefore quantitative reverse transcription-polymerase chain reaction (qRT-PCR) analyses were performed (Fig 4). For four catalase-encoding genes, a strong induction was observed after $\mathrm{H}_{2} \mathrm{O}_{2}$ treatment in the WT (BC1G_12856.1, BC1G_02407.1, BC1G_13021.1, and BC1G_01968.1) and for two catalase-encoding genes a weak induction was observed (BC1G_01095.1 and BC1G_09386.1). While BC1G_12856.1 and $\mathrm{BC} 1 \mathrm{G} \_01968.1$ were specifically induced using $\mathrm{H}_{2} \mathrm{O}_{2}$ as stressor, BC1G_02407.1, BC1G_01095.1, and BC1G_13021.1 were induced after oxidative and osmotic stress treatment. For BC1G_12146.1, no clear induction was observed. As indicated by a differential expression pattern, four catalase-encoding genes that are induced upon stress-treatment in the WT depend on BcSak1. The expression pattern of one peroxisomal catalase (BC1G_01968.1) was the same in $\Delta$ bcsak1 and WT, although the induction after $\mathrm{H}_{2} \mathrm{O}_{2}$ treatment was slightly reduced in the mutant. Another peroxisomal catalase (BC1G_01095.1) was generally induced in $\Delta$ bcsak 1 under all conditions. In contrast, the $\mathrm{H}_{2} \mathrm{O}_{2}$-dependent induction of the genes bccat2 ( $\mathrm{BC} 1 \mathrm{G}_{-}$

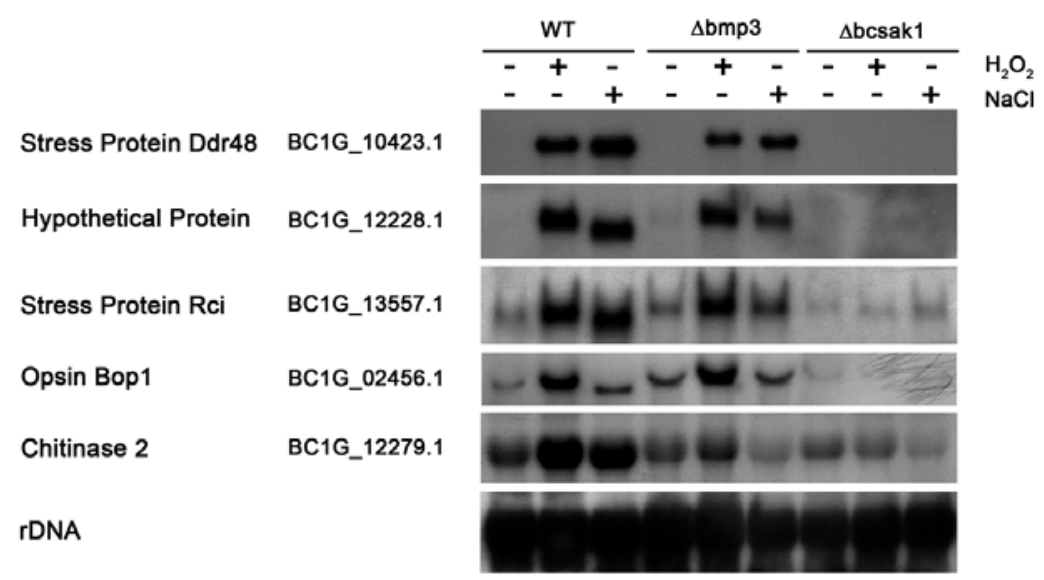

Fig. 3. Expression analysis showing the regulation of stress induced BcSak1-dependent genes. Cultivation under nonstress conditions was performed in Czapek Dox medium. Oxidative stress was induced by adding $10 \mathrm{mM} \mathrm{H}_{2} \mathrm{O}_{2}$ and osmotic stress was induced by adding $1 \mathrm{M} \mathrm{NaCl}$ for $30 \mathrm{~min}$. $\mathrm{rDNA}$ was used as loading control. 
12856.1) and bccatC (BC1G_02407.1) was completely missing, while the last catalase-encoding gene (BC1G_13021.1) was highly induced even under nonstress conditions in $\Delta$ bcsak1. Summarized, the catalase-encoding genes can be divided into four different groups; there are two genes whose induction is BcSak1 dependent, two genes whose transcription level is generally induced in the mutant, one gene that is regulated the same in WT and the mutant, and two genes that are not expressed differentially at all.

\section{Deletion mutants of stress-induced target genes of BcSak1 show no striking phenotype.}

Several BcSak1-dependent genes have already been functionally characterized in other studies. Among them is the gene bccat2 (BC1G_12856.1), which encodes an extracellular catalase (Schouten et al. 2002), bcmtdh (BC1G_09259.1), which encodes a mannitol dehydrogenase (Dulermo et al. 2010), and bcregl (BC1G_11680.1), which encodes a putative transcripttional regulator (Michielse et al. 2011). While the $\Delta$ bccat 2 and the $\Delta$ bcmtdh deletion mutants show no conspicuous morphological phenotype, the $\Delta$ bcreg 1 deletion mutant resembles the phenotype of $\Delta$ bcsak 1 in some aspects, as it shows no conidiation and is nonpathogenic.

To characterize further individual target genes of BcSak1, in this study, three BcSak1-dependent genes that are induced in response to stress were deleted by homologous recombination. These genes encode for the stress protein Ddr48 (BC1G_ 10423.1), the opsin Bop1 (BC1G_02456.1), and a hypothetical protein (BC1G_12228.1). Ddr48 is a DNA-damage response protein that is induced under different stress environments in $S$. cerevisiae and Candida albicans (Dib et al. 2008; McClanahan and McEntee 1986). Knock-out experiments proved that it is essential for filamentation, stress response, and viability, but not for pathogenicity of $C$. albicans, while there is no drastic effect in S. cerevisiae (Treger and McEntee 1990). Opsins are a class of retinal-binding, seven transmembrane helix proteins that function as light-responsive ion pumps or sensory receptors. Homologs of bopl have already been functionally characterized in Neurospora crassa, Leptosphaeria maculans, and Fusarium fujikuroi (Bieszke et al. 1999; Estrada and Avalos 2009; Idnurm and Howlett 2001). Although there is a light and conidiation-based regulation of the respective genes, no mor- phological alteration was observed for either mutant. A BLAST search with the sequence coding for the hypothetical protein (BC1G_12228.1) showed that this protein seems to be conserved in filamentous fungi (data not shown). However, no homolog has been functionally characterized so far.

For the deletion of the corresponding genes in B. cinerea, knock-out fragments were cloned containing a nourseothricin or hygromycin resistance cassette, respectively, flanked by about $1 \mathrm{~kb}$ of the promoter and terminator sequence of the particular genes (Supplementary Fig. S4). The flanking regions were amplified by PCR, adding overhangs either to clone them via restriction and ligation into the vector pNR1 (bopl) or to clone them into the vector pRS426, using the yeast recombinetional cloning technique ( $d d r 48, \mathrm{BC}_{1} \mathrm{G}_{-}$ 12228.1) (Colot et al. 2006). After transformation and three to five rounds of single-spore isolation, three independent deletion mutants of each gene were purified and characterized. The successful deletion was verified by diagnostic PCR analyses and single integration of the corresponding knock-out fragment was proven using Southern hybridization. To characterize the mutants, their differentiation, their stress response, and their virulence were compared with the WT. None of the mutants showed any differentiation defect. When grown in light, the mutants produced the same quantity of conidia as the WT, and when grown in darkness, they produced sclerotia regularly (Fig. 5A). The stress response of the mutants was also unaffected. In a plate assay, the growth rate of the mutants was compared with the WT and with the $\Delta$ bcsak1 deletion mutant on media supplemented with oxidative and osmotic stressors $\left(5 \mathrm{mM} \mathrm{H}_{2} \mathrm{O}_{2}, 10 \mathrm{mM} \mathrm{H}_{2} \mathrm{O}_{2}, 1 \mathrm{M} \mathrm{NaCl}, 1 \mathrm{M}\right.$ $\mathrm{KCl}, 1 \mathrm{M}$ glucose). After 3 days, the mutants showed WTlike growth rates on all tested media, whereas the $\Delta$ bcsak1 deletion mutant was strongly impaired on media containing any stressor (Fig. 5B). The $\Delta$ bcsak 1 deletion mutant was unable to infect unwounded plant tissue, so the mutants were used to perform pathogenicity assays (Fig. 5A). Since the $\Delta$ bcsak1 deletion mutant does not produce any conidia, mycelial plugs were used for all the strains to inoculate bean leaves. The pathogenicity assay showed that the mutants were not impaired in virulence. They were able to infect unwounded plant tissue as efficiently as the WT. In conclusion, although the tested genes were clearly induced in response to
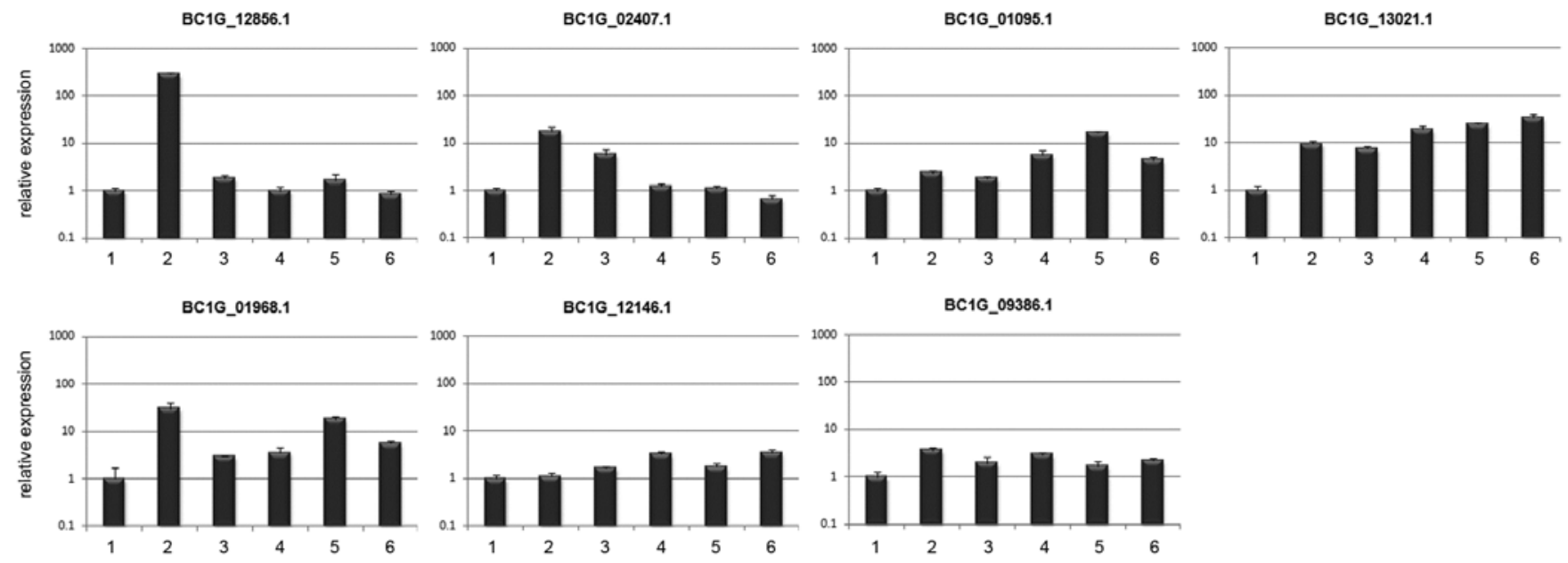

Fig. 4. Expression analysis showing the regulation of seven catalase-encoding genes in response to stress treatment in Botrytis cinerea WT and $\Delta$ bcsak 1 . Cultivation under nonstress conditions was performed in Czapek-Dox medium. Oxidative stress was induced by adding $10 \mathrm{mM} \mathrm{H}_{2} \mathrm{O}_{2}$ and osmotic stress was induced by adding $1 \mathrm{M} \mathrm{NaCl}$ for $30 \mathrm{~min}$. The expression of the catalase encoding genes was measured by real time PCR, using the genes actA, tub and $e l o n$ gation factor as reference genes. The indicated values are means of two technical replicates, and are normalized to the expression in wild type without further treatment; standard deviations are indicated by the error bars. $\left(1=\mathrm{WT}, 2=\mathrm{WT}+\mathrm{H}_{2} \mathrm{O}_{2}, 3=\mathrm{WT}+\mathrm{NaCl}, 4=\Delta \mathrm{bcsak} 1,5=\Delta \mathrm{bcsak} 1+\mathrm{H}_{2} \mathrm{O}_{2}, 6=\right.$ $\Delta$ bcsak $1+\mathrm{NaCl})$ 
stress in B. cinerea in a BcSak1-dependent manner, no striking phenoltype could be detected for the deletion mutants in this study.

\section{BcSak1 is distributed in the cytoplasm} after oxidative stress treatment but localizes to the nucleus after osmotic stress treatment.

To analyze the mode of regulation of BcSak1 in $B$. cinerea, an N-terminal fusion construct of bcsakl with $g f p$ (green fluorescent protein gene) was created. The coding region of bcsakl was cloned into the vector pNAH-OGG (Schumacher in press) using the yeast recombinational cloning technique. To achieve optimal fluorescence, a $g f p$ version was used that is codon-optimized for $B$. cinerea (Leroch et al. 2011). The fusion construct is controlled by the oliC promoter of $A$. nidulans and the glucanase terminator of $B$. cinerea. This promoter and terminator combination was used since no fluorescence could be observed using the native bcsakl-promoter to control expression of the construct, although the phenotype of the $\Delta$ bcsak1 deletion mutant was restored (data not shown). The construct was transformed into the deletion strain $\Delta$ bcsak1. Although there was constitutive expression of the fusion construct using the oliC promoter, its transformation fully restored the phenotype of the bcsakl deletion. The strain $\Delta$ bcsak1:gfp-bcsak1 produced conidia again, was able to grow on media containing osmotic and oxidative stress (Supplementary Fig. S5), and was fully virulent on unwounded plant tissue (Fig. 5A). Additionally, BcSak1 target genes were induced in the complemented strain after $\mathrm{H}_{2} \mathrm{O}_{2}$-treatment, while there was no induction in the untreated control (Supplementary Fig. S6). Therefore the complemented strain was used to determine the localization of BcSak1 in $B$. cinerea hyphae. Droplets $(10 \mu \mathrm{l})$ of a conidial suspension $\left(10^{5}\right.$ spores per milliliter) of the $\Delta$ bcsak 1 :gfp-bcsak 1 mutant were placed on a glass slide, and conidia were allowed to germinate overnight. Microscopic analyses of the germinated conidia showed that, in these cells, the SAPK localized primarily to the cytosol but was not excluded from the nucleus (Fig. 6). To analyze whether the localization of BcSak1 changes in response to stress treatment, its localization was followed after exposure of those germlings to oxidative and osmotic stress. In a control experiment in which water was added to the cultures, the localization of BcSak1 did not change. However, the localization of BcSak1 differed in response to oxidative and osmotic stress treatment (Fig. 6); whereas $\mathrm{BcSak} 1$ remained in the cytoplasm in response to oxidative stress treatment $\left(10 \mathrm{mM} \mathrm{H}_{2} \mathrm{O}_{2}\right.$ and $500 \mu \mathrm{M}$ menadione), it rapidly and markedly accumulated in the nucleus after stimulation by osmotic stress $(0.5 \mathrm{M} \mathrm{NaCl}$ and $1 \mathrm{M}$ sorbitol). The association of the GFP signal to the nuclei is shown in Figure 6B, using Hoechst staining of nuclei. This nuclear localization was transient, however, as the SAPK redistributed to the cytosol about 20 to $30 \mathrm{~min}$ after applying the stressor (Fig. 6A; Supplementary movie). These findings indicate that, although the regulatory output is similar during different stress situations (inductions of mostly the same target genes), the localization of BcSak1 seems to depend on the type of stressor applied.

\section{BcSak1 associates to the nucleus only in early stages of infection.}

To analyze the localization of BcSak1 during the infection process of $B$. cinerea, bean leaves were inoculated with droplets of a conidial suspension of the $\Delta$ bcsak1:gfp-bcsak1 mutant, and the infection area was observed at several time points $(18,22,32$, and $48 \mathrm{~h}$ postinoculation [hpi]), using a confocal laser scanning microscope (Fig. 7). These analyses revealed that BcSak1 localized to the nucleus in the early stages of infection, while the fungus still grew across the epidermis or during penetration. This localization had already begun at 18 hpi, although at that time, the signal in the nucleus was very weak. The fluorescence signal in the nucleus intensified at 22 and $32 \mathrm{hpi}$, due to a stronger accumulation of BcSak1 in the nucleus at these time points. At $48 \mathrm{hpi}$, when the fungus was growing within the plant tissue, accumulation of BcSak1 in the nucleus was no longer detectable and the protein was distributed widely in the cytosol.

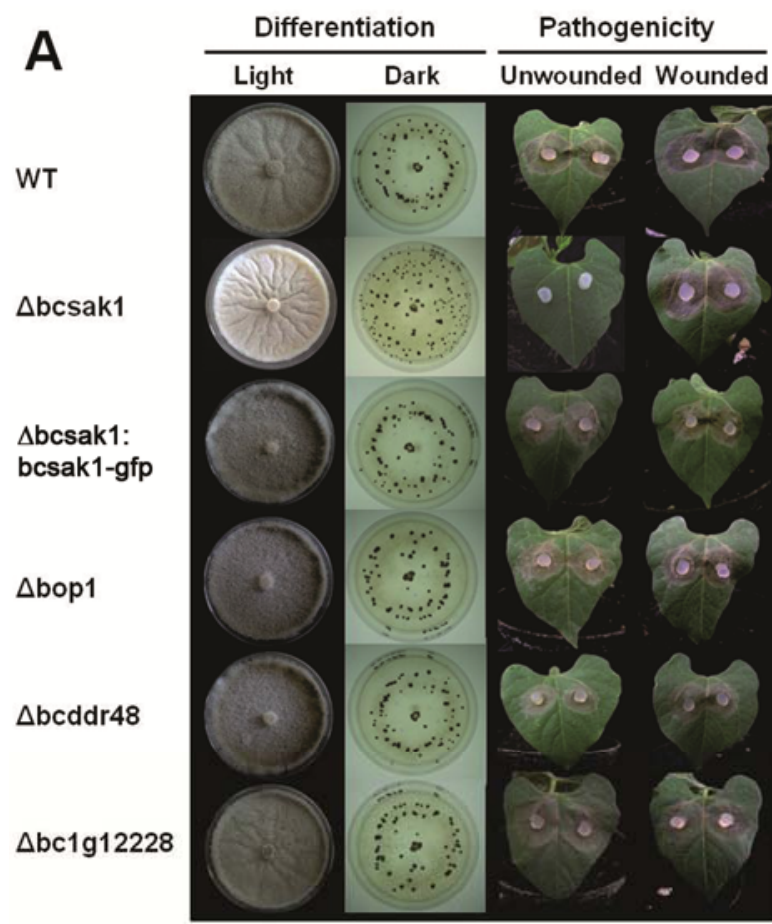

B

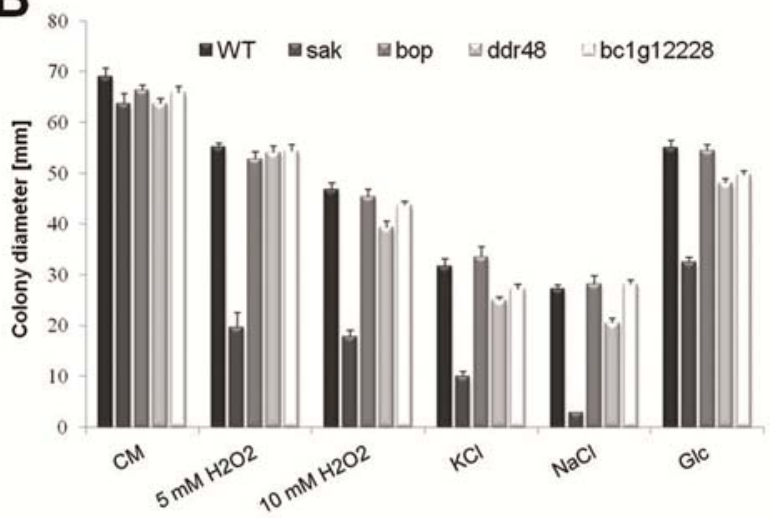

Fig 5. Comparison of differentiation, growth and virulence of Botrytis cinerea B05.10 WT, $\Delta$ bcsak1, $\Delta$ bcsak1:bcsak1-gfp, $\Delta$ bop1, $\Delta$ bcddr48, and $\Delta \mathrm{bc} \lg 12228$. A, For analysis of light-dependent differentiation, strains were cultivated on complete medium (CM) for 7 days with a cycle of $12 \mathrm{~h}$ of light and $12 \mathrm{~h}$ of darkness (light) or for 3 weeks in complete darkness (dark). For pathogenicity tests young bean leaves were inoculated using mycelial plugs of the particular strains. Half of the leaves were injured using an injection needle prior to infection (wounded). Representative photographs of four different experiments, taken $48 \mathrm{~h}$ after the infection, are shown. B, Plate assays showing growth rates of the particular strains on stress-causing media. As a control $\mathrm{CM}$ was used, oxidative stress was induced using $5 \mathrm{mM} \mathrm{H}_{2} \mathrm{O}_{2}$, and $10 \mathrm{mM} \mathrm{H}_{2} \mathrm{O}_{2}$, osmotic stress was induced using $1 \mathrm{M} \mathrm{KCl}, 1 \mathrm{M} \mathrm{NaCl}$, and $1 \mathrm{M}$ glucose. Colony diameters were measured 3 days after the inoculation. The indicated values are means of five different plates; standard deviations are indicated by the error bars. 
Stress-induced target genes of BcSak1 are induced during infection.

As BcSak1 is important for pathogenicity and localizes to the nucleus during infection, the expression of six stress-induced BcSak1 target genes was analyzed during the infection process (bop1, ddr48, bclg12228, bcmtdh, rcil, chitinase2). Therefore, bean leaves were inoculated using mycelial plugs of different strains. Beside the WT and $\Delta$ bcsak1, the three knock-out strains of BcSak1 target genes ( $\Delta$ bop $1, \Delta \mathrm{ddr} 48$, and $\Delta \mathrm{bc} 1 \mathrm{~g} 12228$ ) as well as $\Delta$ bcsak1:gfp-bcsak1 were included in these analyses.
Because $\Delta$ bcsak1 is unable to infect unwounded plant tissue (Fig. 5A), half of the leaves were wounded prior to infection. Primary lesions were excised $48 \mathrm{~h}$ after infection, and RNA was extracted and analyzed by Northern blot analyses.

These expression analyses revealed that all tested stress-dependent $\mathrm{BcSak} 1$ target genes were induced during infection in the WT. In contrast, in primary lesions of the $\Delta$ bcsak 1 deletion mutant, the induction of these genes was absent (Fig. 8). Wounding of the bean leaves had no influence on the expression of the BcSak1 target genes in the WT, and deletion of
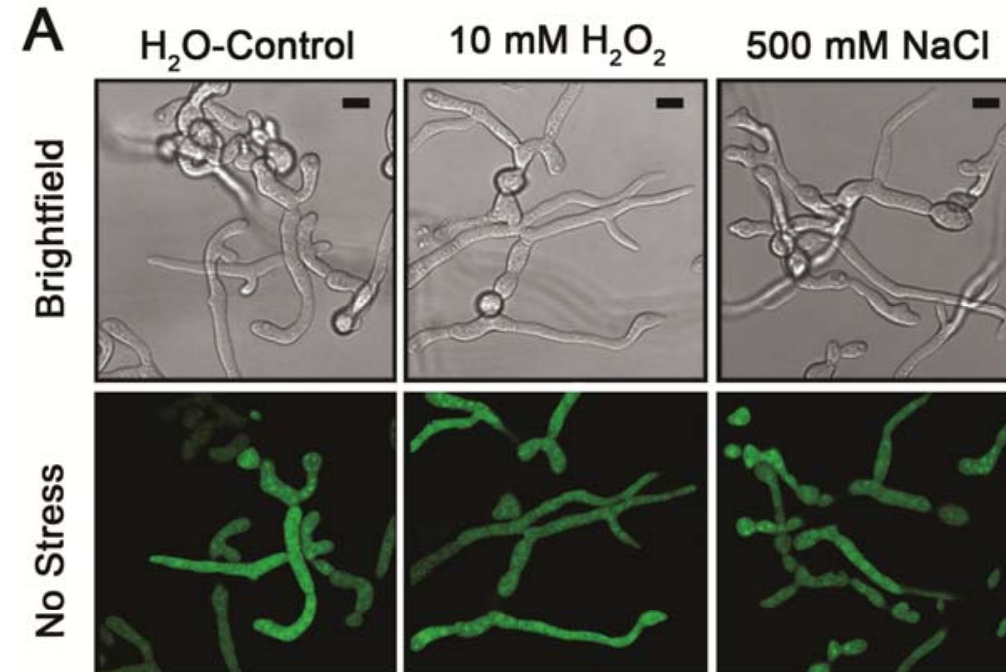

\section{M Sorbitol}
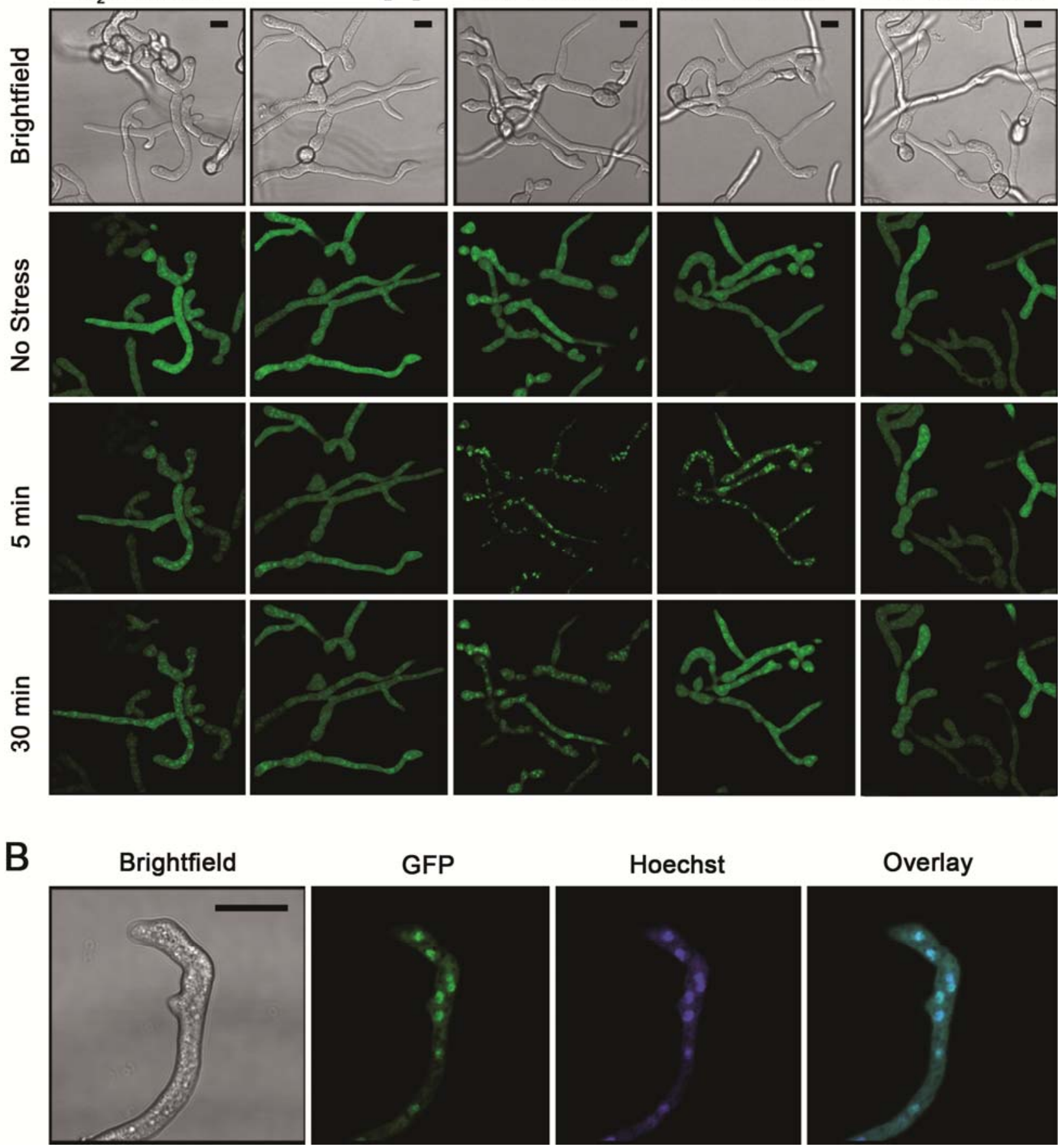

Fig. 6. Cellular localization of the BcSak1 protein in response to different stresses. Protein localization was determined by fluorescence microscopy in strains expressing a BcSak1-GFP (green fluorescent protein) gene fusion. Droplets (10 $\mu \mathrm{l})$ of a conidial suspension (10 ${ }^{5}$ conida/ml) of $\Delta \mathrm{bcsak1:bcsak1-gfp} \mathrm{were}$ placed on a glass slide and were allowed to germinate overnight. A, Time course experiment in which localization of the stress-activated protein kinases was followed before and after the addition of different stressors as indicated. B, To verify that BcSak1 translocates to the nuclei, NaCl-treated hyphae were stained using Hoechst 33342 before visualization. Bars $=10 \mu \mathrm{m}$. 
neither BcSak1 target gene influenced the induction of another one. By introducing bcsakl-gfp into the $\Delta$ bcsak1 deletion mutant, the induction of the BcSak1 target genes could be restored. However, for two genes, a stronger expression could be
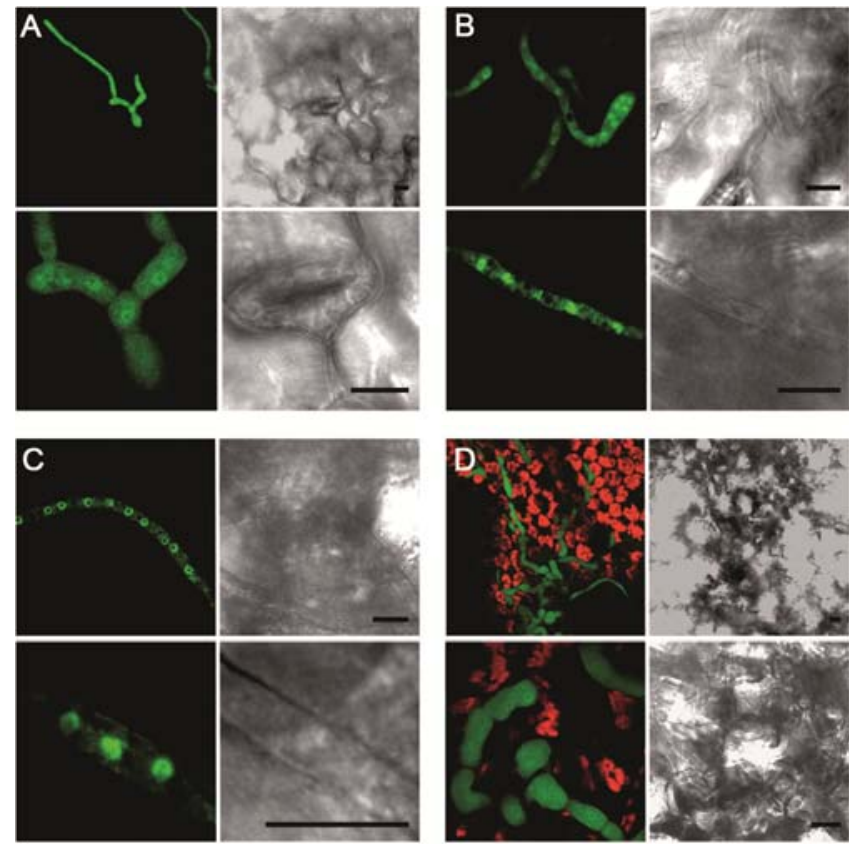

Fig. 7. Cellular localization of the BcSak1 protein during infection Protein localization was determined by fluorescence microscopy in strains expressing a BcSak1-GFP (green fluorescent protein) gene fusion. Young bean leaves were inoculated with $7.5 \mu \mathrm{l}$ of a conidial suspension $\left(2 \times 10^{5}\right.$ conidia/ml) of the strain $\Delta$ bcsak1:bcsak1-gfp, and infection areas were analyzed microscopically at different time points. GFP fluorescence is shown in green; chlorophyll fluorescence is shown in red; Bars $=10 \mu \mathrm{m}$ A, 18 h postinoculation (hpi); B, 22 hpi; C, 32 hpi; and D, 48 hpi. detected ( $d d r 48, b c m t d h)$ that might result from constitutive expression of the fusion construct.

\section{BcSak1 influences regulation of secondary metabolism genes} of $B$. cinerea during infection.

Though being induced in planta, no stress-induced BcSak1-dependent target genes analyzed in this study were involved in pathogenicity of $B$. cinerea. However, the macroarrays revealed that several genes involved in secondary metabolism were also regulated by BcSak1. B. cinerea produces two major phytotoxic secondary metabolites, the sesquiterpene botrydial and botcinic acid and its botcinin derivatives (Colmenares et al. 2002; Tani et al. 2005). Botrydial has been reported to induce chlorosis and seems to facilitate penetration and colonization. Furthermore, botrydial has also been shown to be a strain-dependent virulence factor (Siewers et al. 2005). One gene of each gene cluster (bcboa6 and bcbot4) appeared in the macroarray analysis to be BcSak1 dependent. Therefore dependency of both gene clusters on BcSak1 during infection was analyzed. qRT-PCR analyses were performed to compare the expression of two genes of each gene cluster (bcbot1 and bcbot4 for botrydial and bcboa4 and bcboa7 for botcinic acid) in primary lesions of the WT, the $\Delta$ bcsak1 deletion mutant, and $\Delta$ bcsak1:gfp-bcsak1 (Fig. 9).

These analyses showed that both gene clusters depended on BcSak1. However, their regulation during infection was different; while the in planta expression of genes in the botcinic acid gene cluster was up-regulated in $\Delta$ bcsak 1 compared with the WT, the expression of genes in the botrydial gene cluster was clearly down-regulated. Complementation of $\Delta$ bcsak1 with bcsakl-gfp reduced the expression level of the botcinic acid genes and increased the expression level of the botrydial genes. However, in the strain $\Delta$ bcsak1:gfp-bcsak1, expression of boa4 and boa 7 was still slightly induced and bot 1 was overexpressed. As discussed above, this might result from the constitutive expression of the fusion construct.

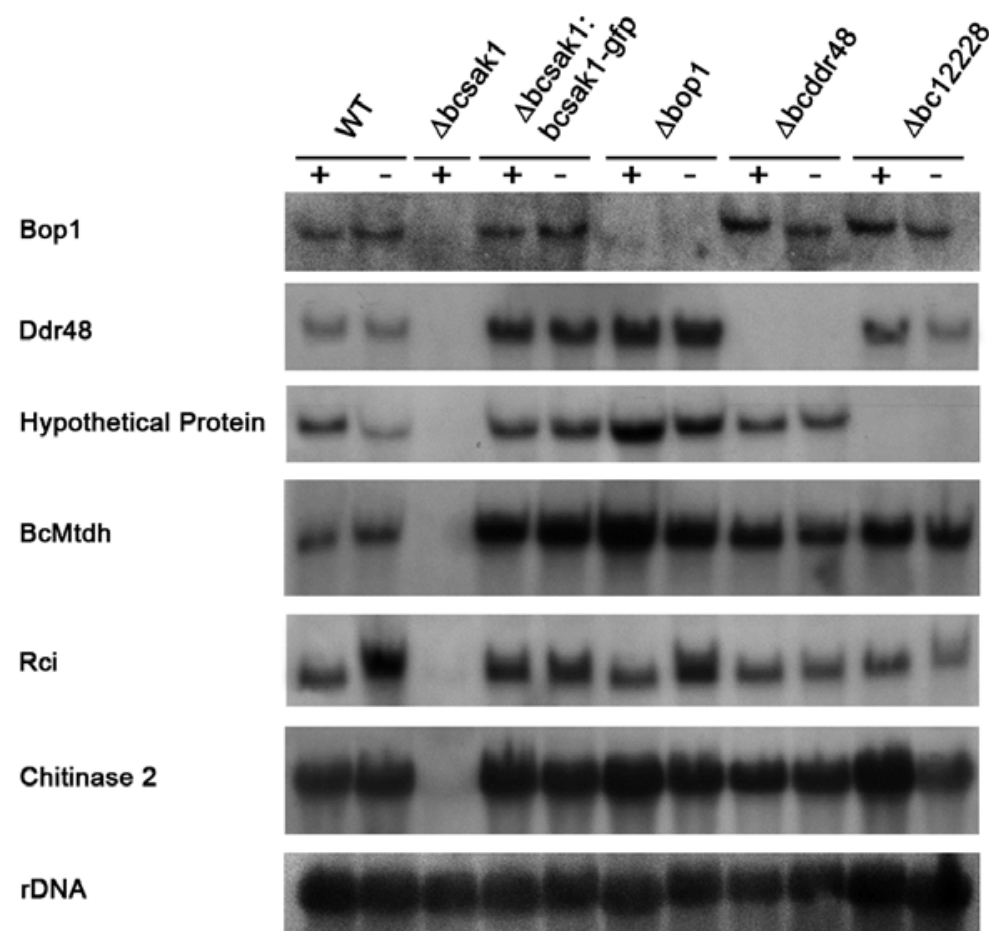

Fig. 8. Analysis of the expression of BcSak1-dependent genes during the infection of Botrytis cinerea B05.10 WT, $\Delta$ bcsak1, $\Delta$ bcsak1:bcsak1-gfp, $\Delta$ bop1, $\Delta \mathrm{bcddr} 48$, and $\Delta \mathrm{bc1g} 12228$. Young bean leaves were inoculated using mycelial plugs of the particular strains and were either wounded (+) or not (-) prior to infection. As $\Delta$ bcsak1 is unable to infect unwounded plant tissue, only material from wounded plants could be analyzed in this strain. Lesions were excised and analyzed $48 \mathrm{~h}$ postinoculation. rDNA was used as loading control. 


\section{$\Delta$ bcsak1 produces fewer phytotoxins in axenic culture than the WT.}

Because the gene expression of secondary metabolite genes in the $\Delta$ bcsak1 deletion mutant was disturbed during the infection process, the production of secondary metabolites in axenic cultures was analyzed. Therefore, $\Delta$ bcsak1 and WT were grown on malt agar medium and were incubated at $25^{\circ} \mathrm{C}$. After 10 days, the secondary metabolites produced by the strains were identified and were quantified.

These analyses established that, also in axenic culture, the $\Delta$ bcsak1 deletion mutant is clearly affected in its secondary metabolism, even though the regulation seemed to differ from that in planta (Table 1). Although, during infection, genes of the botcinic acid gene cluster are up-regulated in the $\Delta$ bcsak 1 deletion mutant, no botcinins were detected in the culture extracts of the deletion mutant. In contrast, the production of botryanes could still be detected. However, the amount of this group of secondary metabolites was rather small compared with the WT. Interestingly, among the botryanes produced by $\Delta$ bcsak1, a compound was isolated that is normally not produced by $B$. cinerea. This compound was identified as deacetyldihidrobotrydial ( $2 \mathrm{mg}$ ), which is notable because, typically, all botrydial derivatives of $B$. cinerea bear an acetyl group at $\mathrm{C}$-4. It seems, therefore, that, in general, the toxin secondary metabolism and especially the acetate pathway of $\Delta$ bcsak 1 is affected, as no polyketides and only a trace amount of fatty acid (approximately $1 \mathrm{mg}$, not shown) were produced by the deletion mutant.

In conclusion, the data indicate that, in $B$. cinerea, the role of BcSak1 is not restricted to regulation of the stress response, but instead, has extended to include the regulation of more general metabolic functions during growth and pathogenesis.

\section{DISCUSSION}

When attacked by pathogens, plants produce large amounts of ROS during the oxidative burst (Heller and Tudzynski 2011). SAPK homologous to yeast's Hog1 have been shown,
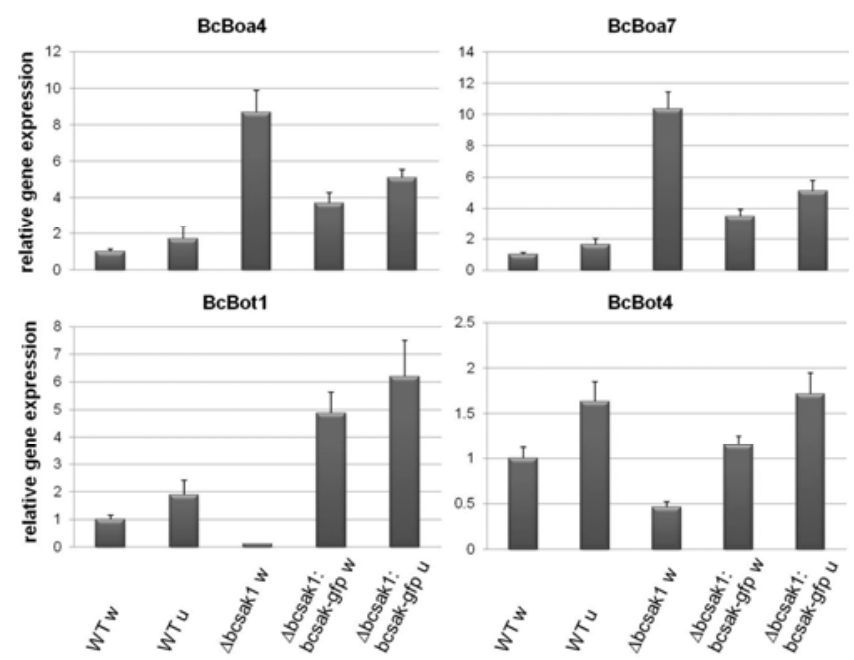

Fig. 9. Expression of botcinic acid and botrydial biosynthesis genes in Botrytis cinerea B05.10 WT, $\Delta$ bcsak1, and $\Delta$ bcsak1:bcsak1-gfp during infection. Young bean leaves were inoculated using mycelial plugs of the particular strains. The expression of the botcinic acid biosynthesis genes bcboa 4 and bcboa7 and the botrydial biosynthesis genes bcbot 1 and bcbot 4 was measured by real-time polymerase chain reaction, using the genes $a c t A, t u b$, and elongation factor as reference genes. The indicated values are means of two technical replicates and are normalized to the expression in wild-type infection on wounded leaves. Standard deviations are indicated by the error bars. A biological replicate yielded equal results. $\mathrm{w}=$ wounded, $\mathrm{u}=$ unwounded. in fungi, to be involved in the transcriptional regulation of stress response genes and, therefore, might also be involved in the oxidative stress response (Chen et al. 2003; Eaton et al. 2010; Moriwaki et al. 2006). The deletion mutant of the Hog1 homolog of $B$. cinerea, bcsakl, shows a very drastic phenotype (Segmüller et al. 2007); it is disturbed in differentiation and completely apathogenic on unwounded plant tissue. Therefore, a correlation was assumed between the oxidative burst as a defense reaction and the apathogenicity of the $\Delta$ bcsak 1 mutant due to a missing oxidative stress response. However, although it had been shown previously that BcSak1 controls the $\mathrm{H}_{2} \mathrm{O}_{2-}$ dependent induction of the gene bccat 2 and, thus, seems to be involved in the activation of some oxidative stress response genes, other stress-induced target genes of this SAPK were unknown.

This study gives a broad overview of genes controlled by BcSak1 during growth in axenic culture and in response to oxidative stress and gives new insight into the regulation of the SAPK in B. cinerea in response to stress and during infection (Fig. 10). It is shown that BcSak1 regulates the transcription of several genes under standard conditions and that the general transcriptional response of $B$. cinerea after $\mathrm{H}_{2} \mathrm{O}_{2}$ treatment depends on the SAPK.

There are two possible reasons for the high proportion of stress response genes among the induced genes in $\Delta$ bcsak1 during normal growth. Either the SAPK directly suppresses the stress response genes under standard conditions in the WT or, more likely, the deletion mutant attempts to compensate for the missing SAPK by inducing stress responsive genes that are not directly dependent on BcSak1. However, among those genes regulated by $\mathrm{BcSak} 1$ under oxidative stress conditions, there are only a few known oxidative stress response genes (e.g., bccat 2 ). The main proportion of genes, controlled by BcSak1, is involved in regulation, differentiation, and general metabolism. Therefore, BcSak1 seems to be involved in redirecting the general transcriptional profile of $B$. cinerea when the fungus is subjected to stress rather than in activating the oxidative stress response specifically. The fact that, besides the gene encoding the extracellular catalase BcCat2, all BcSak1dependent genes analyzed in this study are induced, not only in response to oxidative stress but also in response to osmotic stress, supports the hypothesis that BcSak1 is involved in regulating the general stress response of $B$. cinerea rather than being specific for oxidative stress. This regulation has already been demonstrated for Sty1 (homologous to BcSak1) in the fission yeast Schizosaccharomyces pombe, in which it was shown that the SAPK and the transcription factor Atf1 control a core environmental stress response common to most stresses, while stress-specific responses are less dependent on the Sty1 kinase pathway (Chen et al. 2008).

Table 1. Comparison of secondary metabolites isolated from axenic cultures of Botrytis cinerea B05.10 and $\Delta$ bcsak1 (mg)

\begin{tabular}{lccc}
\hline Compound & B05.10 $^{\mathbf{a}}$ & $\boldsymbol{\Delta b c s a k 1}^{\mathbf{a}}$ & Phytotoxicity $^{\text {Phong }}$ \\
\hline Botrydial (1) & 9 & n.d. & Strong \\
Dihydrobotrydial (2) & 4 & 1.5 & Low \\
Deacetydihidrobotrydial (2a) & n.d. & 2.0 & Low \\
Botryendial (3) & 2 & n.d. & Strong \\
Botrydienalol (4) & 2 & n.d. & Low \\
Botrydienalone (5) & n.d. & 1.2 & Low \\
$\beta$-acetoxy-9 $\beta, 10 \beta$-dihydroxy- & & & \\
probotriane (6) & 1 & n.d. & No \\
Botcinic acid (7) & 5 & n.d. & Strong \\
Botcinin A (8) & 11 & n.d. & Strong \\
Botrylactone (9) & $<1$ & n.d. & No \\
Botrylactone (10) & 1 & n.d. & No \\
\hline
\end{tabular}

${ }^{a}$ n.d. indicates not detectable. 
However, even though BcSak1 seems to be responsible for the regulation of general stress response genes in $B$. cinerea, localization studies using a fusion construct of BcSak1 and GFP proved that the mode of action of the SAPK depends on the stress being applied. Accordingly, the SAPK translocates to the nucleus in response to osmotic stress, while it remains distributed in the cytosol during oxidative stress treatment. This is in marked contrast to A. nidulans and Trichoderma harzianum, in which it was shown that SakA and ThHog1, respectively, also localize to the nucleus in response to oxidative stress (Delgado-Jarana et al. 2006; Lara-Rojas et al. 2011). Nuclear localization of active MAPK seem to be a general feature, as the nuclear localization of the cell integrity MAPK (MpkA) under iron depletion has been shown recently in $A$. fumigatus (Jain et al. 2011).

In the expression analyses performed here, it was shown that in $B$. cinerea the outcome of regulatory events after oxidative and osmotic stress treatment is similar. Still there are BcSak1dependent genes that are specifically induced upon oxidative stress treatment (as shown for bccat2), and similarly, there will probably be BcSak1-dependent genes specifically induced upon osmotic stress treatment (not identified in this study). Therefore, we propose that BcSak1 generally acts via activation of transcription factors in response to stress, while it additionally modifies the transcriptional machinery within the nucleus directly after osmotic stimulation. Such a mode of action has already been described for $\operatorname{Hog} 1$ of $S$. cerevisiae. As shown by chromatin precipitation, besides direct phosphorylation of several transcription factors, active Hog 1 also associates at stress-responsive promoters through such transcription factors (Alepuz et al. 2001). Once at the promoters, Hog1 serves as a platform to recruit general transcription factors, chromatin-modifying activities and RNA PolII. In addition, the SAPK pathway has a role in elongation (Proft et al. 2006); at the stress-responsive open reading frames, Hog1 recruits the RSC chromatin-remodeling complex to modify nucleosome organization (Mas et al. 2009). A similar role for Sty1 has also been proposed in fission yeast (Sanso et al. 2011). Here, the MAPK and Atf1 in combination with its heterodimeric partner Pcr1 regulate diverse processes, mainly in the nucleus. They participate in promoting recombination at some hot spots and in assembly of heterochromatin at the mating locus. Although the nuclear localization of Hog1 homologs in filamentous fungi is a good indication of similar functions, it remains to be elucidated if SAPK have maintained these regulatory abilities.

A good candidate as the transcription factor downstream of BcSak1 is the BcSak1-dependent putative transcriptional regulator BcReg1 (Michielse et al. 2011) (Fig. 10). The corresponding deletion mutant shows some phenotypic similarities to $\Delta$ bcsak1 because it is sensitive to oxidative stress and is blocked during formation of conidia. Regarding secondary metabolite production, this deletion mutant produces no detectable levels of the sesquiterpene botrydial and the polyketide botcinic acid. Furthermore, it shows reduced virulence, as it is not able to cause necrotic lesions, although it is still able to penetrate the plant tissue. However, a direct interaction of BcReg1 and BcSak1 has not been shown. A connection between BcSak1 and the transcription factor BcAtf1, which is a downstream factor of the SAPK in Schizosaccharomyces pombe and A. nidulans (Lara-Rojas et al. 2011; Wilkinson et al. 1996), has been postulated recently (Temme et al. in press) (Fig. 10). Although $\Delta$ bcatf1 mutants are not hypersensitive either to osmotic or to oxidative stress, both signaling components share several stress-responsive target genes. Additionally, both BcSak1 and BcAtf1 are regulators of differentiation. Their roles in these processes, however, are almost inverse; $\Delta$ bcatf1 mutants still produce fewer conidia but no sclerotia. They show extremely vigorous growth in axenic culture and increased colonization efficiency on different host plants and tissues. Additionally, unlike $\Delta$ bcsak1 mutants, the $\Delta$ bcatf1 deletion mutants produce significantly elevated levels of phytotoxins in axenic culture. Other transcription factors responsible for the transduction of the BcSak1 signal after oxidative stimulation remain to be identified. The transcription factor Bap1 is the major regulator of the oxidative stress response but is probably independent of the SAPK, because the deletion mutant does not have any morphological similarities with $\Delta$ bcsak1 (Temme and Tudzynski 2009). However, as Bap1 also shares a few target genes with BcSak1, at least some crosstalk between both signaling components is probable. For the identification of further unknown interaction partners of BcSak1, a cDNA library screening via yeast twohybrid will be performed.

In localization studies performed in this work, it was shown, that BcSak1 associates to the nucleus during early stages of infection. This localization can only be observed while the fungus is growing on the epidermis or during penetration of the plant tissue. As soon as it grows inside the plant cells and lives as a saprotroph, the SAPK translocates back to the cytoplasm. The fact that BcSak1 localizes to the nucleus in response to osmotic stress in axenic culture might indicate that there is osmotic stress for the pathogen during early stages of infection. However, this might be true for the penetration event but certainly not during epiphytic growth. An alternative explanation could be that beside osmotic stress, other signals cause nuclear association of BcSak1. Such signals

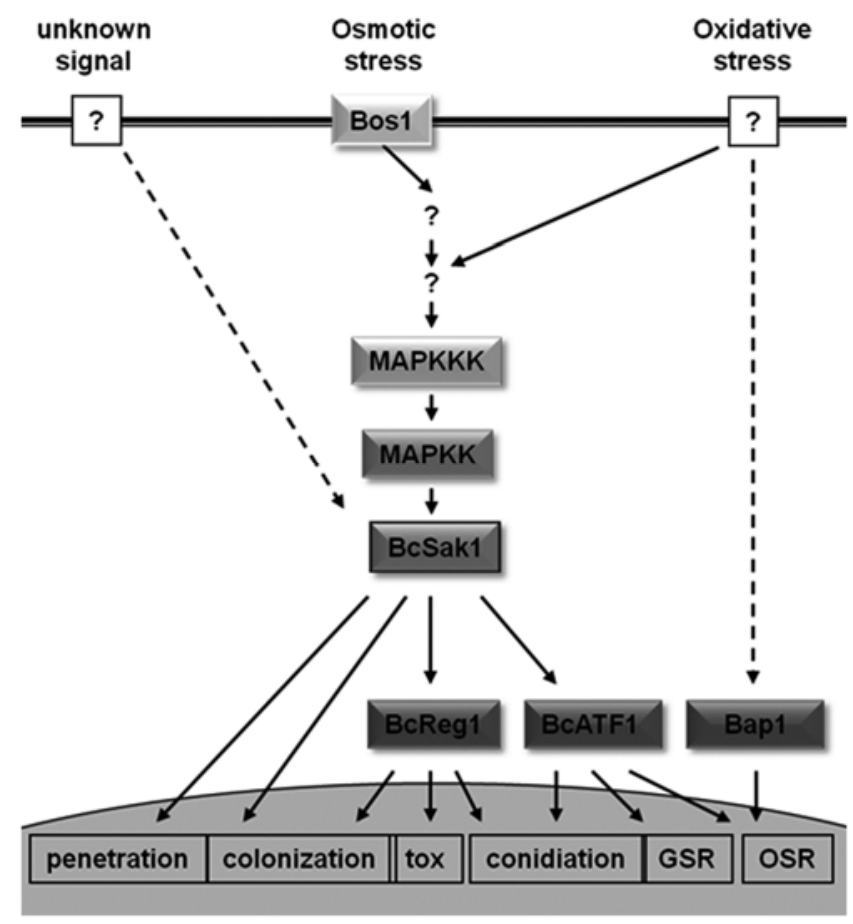

Fig. 10. Hypothetical model showing the regulatory network of BcSak1 in Botrytis cinerea. A known (negative) regulator of BcSak1 is the histidine kinase Bos1 (Liu et al. 2008; Viaud et al. 2006), which seems to be mainly involved in osmotic stress tolerance. Other upstream components have been identified in the genome but not functionally characterized. The major regulator of the oxidative stress response independent of BcSak1 is the transcription factor Bap1. However, some genes regulated differentially after oxidative stress treatment also depend on BcSak1. Potential transcription factors downstream of BcSak1 are BcReg1 and BcAtf1, even though both differ in their function. Beside osmotic and oxidative stress, other signals, especially during infection, seem to affect the regulation of $\mathrm{BcSak} 1$. tox $=$ toxin production, GSR $=$ general stress response, OSR = oxidative stress response. 
might be fungal programmed cell death-inducing factors secreted by plants as introduced by Shlezinger and associates (2011), who proved that fungal strains showing overstimulated programmed cell death are reduced in pathogenicity and that the fungal anti-apoptotic machinery is of special importance during early stages of infection.

Because the $\Delta$ bcsak1 deletion mutant is unable to differentiate appressoria-like structures (Segmüller et al. 2007), the formation of these penetration structures could also be regulated by nuclear-associated BcSak1 during infection. The nuclear localization of SakA during other differentiation processes has already been demonstrated for A. nidulans, in which SakA interacts with AtfA in the nucleus during conidiophore development (Lara-Rojas et al. 2011).

The fact that the deletion mutant $\Delta$ bcsak1 is able to infect wounded plant tissue, although in this case an oxidative burst still takes place (Segmüller et al. 2007), has already suggested that it is not the missing oxidative stress response in the $\Delta$ bcsak1 deletion mutant that leads to its apathogenicity. However, since aggressiveness of lesion spread of the $\Delta$ bcsak 1 deletion mutants varies between different pathogenicity tests (obviously depending on the fitness of the host) and different mutants, the oxidative stress response may still be required for colonization. In the special case of penetration phase, however, it seems to be the influence of BcSak1 on differentiation programs that causes the defect of the deletion mutant. This, especially, may be true, as no stress-induced single target gene of the SAPK with an effect on penetration has been identified so far. Including the genes bccat 2 and $b c m t d h$, five $\mathrm{H}_{2} \mathrm{O}_{2}$-induced BcSak1-dependent single target genes have been characterized in $B$. cinerea, and none of the deletion mutants is affected in development or pathogenicity (Dulermo et al. 2010; Schouten et al. 2002). Only the deletion mutant of the BcSak1-dependent gene bcregl shares some phenotypic similarities with $\Delta$ bcsak1 (discussed above). However, as a putative transcriptional regulator, BcReg1 is probably part of the signaling network downstream of BcSak1 and, thus, also acts as a general regulator of several target genes of the SAPK. Therefore, the reason for the strong phenotype of $\Delta$ bcsak1 seems to be the loss of a whole signaling network composed of several genes, while deletion of single target genes of this network does not have a strong influence.

Recently, it has been shown that BcSak1 controls melanin biosynthesis (Liu et al. 2011). Data presented here indicate that the SAPK generally influences the secondary metabolism of $B$. cinerea. This was shown in planta via expression analyses and in axenic culture via quantitative analyses of secondary metabolites.

In planta, the main secondary metabolite gene clusters of $B$. cinerea are regulated inversely. While genes of the botcinic acid gene cluster are induced in $\Delta$ bcsak1 compared with the WT, genes of the botrydial gene cluster are repressed. Therefore, reduced amounts of botrydial might influence the virulence of $\Delta$ bcsak1. Although both secondary metabolites show high phytotoxicity, it was shown that botcinic acid is not essential for pathogenicity in the WT strain B05.10, and botrydial is a strain-specific virulence factor in the strain T4 but not

Table 2. Fungal mutant strains used in this study

\begin{tabular}{lll}
\hline Strain & \multicolumn{1}{c}{ Genotype } & \multicolumn{1}{c}{ Reference } \\
\hline$\Delta$ bcsak1 & B05.10 $\Delta$ bcsak1::nat1 & Segmüller et al. 2007 \\
$\Delta$ bmp3 & B05.10 $\Delta$ bmp3::hph & Rui and Hahn 2007 \\
$\Delta$ bop1 & B05.10 $\Delta$ bop1::nat1 & This study \\
$\Delta$ bcddr48 & B05.10 $\Delta$ bcddr48::hph & This study \\
$\Delta$ bc12228 & B05.10 $\Delta$ bc12228::hph & This study \\
$\Delta$ bcsak1:gfp-bcsak1 & $\Delta$ bcsak1::gfp-bcsak1 hph & This study \\
\hline
\end{tabular}

in the strain B05.10 (Dalmais et al. 2011; Siewers et al. 2005). Only the simultaneous loss of both secondary metabolites leads to reduced virulence in the strain B05.10. However, quantitative analyses of secondary metabolite production in axenic culture showed that both groups of secondary metabolites, botryanes as well as botcinins, are reduced in $\Delta$ bcsak 1 . While the mutant does not produce any botcinins, it still produces three compounds belonging to the botryanes, but all of them show low toxicity, and two of them are not even produced by the WT. Therefore, the induction of genes of the botrydial gene cluster in $\Delta$ bcsak1 during infection might lead to overproduction of those botryanes without effect on the plant, while there is no production of the actual phytotoxic botrydial. This reduced production of both secondary metabolites in $\Delta$ bcsak1 might contribute to the sometimes observed reduced virulence of the mutant (Segmüller et al 2007). Indeed, preliminary in planta analyses of phytotoxins showed that, in contrast to material infected with the WT, in which botrydial could be identified easily, in material infected with the $\Delta$ bcsak1 mutant, this phytotoxin could not be detected (data not shown). Instead, the mutant produced a mixture of other toxins that remain to be characterized.

This study gives new insight into the regulation of BcSak1 of $B$. cinerea. It was shown that the SAPK is necessary to control the basic reaction of the organism during a stress period. Although the mode of action of the SAPK can differ between different stress environments, the outcome at the transcriptional level is mostly the same. In addition, BcSAK1 has a strong impact on secondary metabolism and on differentiation. The reduced pathogenicity of the deletion mutant seems to be mainly due to the failure to differentiate appressoria. Therefore, the SAK cascade in $B$. cinerea is far more than a stress response pathway, it is a central regulator of basic metabolic and differentiation processes.

\section{MATERIALS AND METHODS}

\section{Fungal strains.}

Strain B05.10 of Botrytis cinerea Pers.:Fr. [Botryotinia fuckeliana (de Bary) Whetzel] is a putative haploid strain obtained after benomyl treatment of a Vitis isolate (Büttner et al. 1994) and is used as host strain for gene replacement experiments and as a wild-type control in all experiments. All other strains used in this study are listed in Table 2.

\section{Media and culture conditions.}

Yeast cells were cultivated in selective dropout (SD) medium (per liter: $20 \mathrm{~g}$ of glucose, $6.7 \mathrm{~g}$ of Difco Yeast Nitrogen Base without amino acids [BD, Franklin Lakes, NJ U.S.A.], $0.77 \mathrm{~g}$ of DO-supplements [Clontech, Mountain View, CA, U.S.A.], pH 5.8). WT and mutant strains were grown on several complex media. Potato dextrose agar (Sigma-Aldrich Chemie, Steinheim, Germany) was supplemented with $10 \%$ homogenized leaves of French bean (Phaseolus vulgaris) (PDAB). Synthetic complete medium (CM) was made according to Pontecorvo and associates (1953). As minimal medium, $\mathrm{CD}$ medium (per liter: $20 \mathrm{~g}$ of sucrose, $1 \mathrm{~g}$ of $\mathrm{KH}_{2} \mathrm{PO}_{4}, 3 \mathrm{~g}$ of $\mathrm{NaNO}_{3}, 0.5 \mathrm{~g}$ of $\mathrm{KCl}, 0.5 \mathrm{~g}$ of $\mathrm{MgSO}_{4} \times 7 \mathrm{H}_{2} \mathrm{O}, 0.01 \mathrm{~g}$ of $\mathrm{FeSO}_{4} \times 7 \mathrm{H}_{2} \mathrm{O}, \mathrm{pH}$ 5.2) or GB5 (per liter, $3.3 \mathrm{~g}$ of Gamborg'sB5 [Duchefa Biochemie BV, Haarlem, the Netherlands], $20 \mathrm{~g}$ of glucose) was used. For conidiation, the strains were incubated for 1 week at $18^{\circ} \mathrm{C}$ under light conditions and, for sclerotia formation, for 4 weeks at $18^{\circ} \mathrm{C}$ in darkness. For DNA preparations, mycelium was grown for 3 to 4 days at $18^{\circ} \mathrm{C}$ on CM agar with a cellulose acetate (cellophane) overlay. Testing of stress sensitivity was performed by inoculating strains on CM plates supplemented with $\mathrm{H}_{2} \mathrm{O}_{2}, \mathrm{NaCl}, \mathrm{KCl}$, and glucose. 
For axenic culture shift experiments and subsequent RNA isolation, the strains were grown for 3 days on CM agar medium covered with cellophane. Malt medium (100 ml, 1.5\%) was then inoculated with homogenized mycelium and was incubated for $14 \mathrm{~h}$ at $18^{\circ} \mathrm{C}$ and $150 \mathrm{rpm}$. The mycelium was harvested using a Nytex membrane and was incubated in defined liquid medium (modified CD medium: [per liter], $20 \mathrm{~g}$ of glucose, $1 \mathrm{~g}$ of $\mathrm{KH}_{2} \mathrm{PO}_{4}, 1 \mathrm{~g}$ of $\mathrm{NaNO}_{3}, 0.5 \mathrm{~g}$ of $\mathrm{KCl}, 0.5 \mathrm{~g}$ of $\mathrm{MgSO}_{4} \times 7 \mathrm{H}_{2} \mathrm{O}, 0.01 \mathrm{~g}$ of $\mathrm{FeSO}_{4} \times 7 \mathrm{H}_{2} \mathrm{O}, \mathrm{pH}$ 5.2) for an additional $24 \mathrm{~h}$ under the same conditions. Flasks with $\mathrm{CD}$ medium including stress-inducing supplements $\left(\mathrm{H}_{2} \mathrm{O}_{2}\right.$ or $\left.\mathrm{NaCl}\right)$ were each inoculated with 2 to $3 \mathrm{~g}$ mycelium and were incubated at $18^{\circ} \mathrm{C}$ and $150 \mathrm{rpm}$ for another $30 \mathrm{~min}$.

For analysis of metabolite production, strains were grown on malt agar medium (per liter, $20 \mathrm{~g}$ of $\mathrm{D}$-glucose, $10 \mathrm{~g}$ of malt extract, $20 \mathrm{~g}$ of agar, $1 \mathrm{~g}$ of peptone, $\mathrm{pH} 6.5$ to 7) at $25^{\circ} \mathrm{C}$ and were used to inoculate petri dishes with solid malt agar medium or roux bottles with modified CD medium (per liter, 50 $\mathrm{mg}$ of D-glucose, $1 \mathrm{~g}$ of yeast extract, $5 \mathrm{~g}$ of $\mathrm{KH}_{2} \mathrm{PO}_{4}, 2 \mathrm{~g}$ of $\mathrm{NaNO}_{3}, 0.5 \mathrm{~g}$ of $\mathrm{MgSO}_{4} \times 7 \mathrm{H}_{2} \mathrm{O}$ and $0.01 \mathrm{~g}$ of $\mathrm{FeSO}_{4} \times 7$ $\mathrm{H}_{2} \mathrm{O}$, pH 6.5 to 7.0 ). In a typical experiment, 10 roux bottles were each inoculated with six mycelial plugs $(1 \mathrm{~cm})$ and were incubated for 9 days at $25^{\circ} \mathrm{C}$. After incubation under fluorescent light, the culture medium was filtered and saturated with $\mathrm{NaCl}$ and was then extracted with ethyl acetate $(3 \times 0.5$ vol. $)$ and washed with water $(3 \times 0.25$ vol. $)$.

For solid medium cultures, 10 petri dishes were inoculated with three mycelial plugs $(1 \mathrm{~cm})$ each and were incubated for 10 days at $25^{\circ} \mathrm{C}$. Then, the solid agar malt medium was cleaned from mycelia and conidia and was extracted with ethyl acetate $(3 \times 0.5 \mathrm{vol}$.), using an ultrasonic bath for $15 \mathrm{~min}$.

The organic extracts from both cultures were dried over $\mathrm{Na}_{2} \mathrm{SO}_{4}$ and were concentrated to dryness. The production of metabolites from fermentations on solid agar malt medium was greater and the extracts purer than those produced by surface culture fermentations. Therefore, all data indicated in the Results and Discussion sections refer to those obtained from fermentations on solid agar malt medium.

\section{Transformation.}

For construction of $\mathrm{p} \Delta \mathrm{bop} 1$ the $5^{\prime}$ (1,185 bp) and $3^{\prime}$ (585 bp) flanking regions of the gene bopl (BC1G_02456.1) were amplified from genomic DNA, using the primer pairs 1 and 2 and 3 and 4, respectively, which contain specific restriction sites. The flanking regions were cloned into the vector pCR2.1-TOPO,

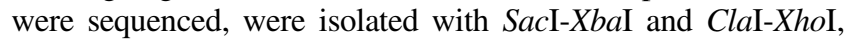
respectively, and were cloned into the corresponding restriction sites of the nourseothricin-resistance vector pNR1 (Malonek et al. 2004). The complete replacement fragment was excised with SacI/XhoI and was used to transform strain B05.10. Knock-out constructs for $d d r 48$ and bclg_12228.1 were obtained using the homologous recombination system in yeast, as described previously (Colot et al. 2006). The $5^{\prime}$ and $3^{\prime}$ regions of $d d r 48$ (736 and $815 \mathrm{bp}$ ) and $b c 1 g \_12228.1$ (950 and $990 \mathrm{bp}$ ) were amplified from genomic DNA using the primer pairs 9 and 10 and 11 and 12 and primer pairs 17 and 18 and 19 and 20, respectively. These primers not only contain sequences to amplify the $5^{\prime}$ and $3^{\prime}$ regions of the corresponding genes but, also, the sequences homologous to the resistance cassette and the yeast plasmid pRS426 (Christianson et al. 1992). The hygromycin resistance cassette containing the hph gene of Escherichia coli under control of the $\operatorname{trpC}$ promoter of $A$. nidulans was generated with primers 25 and 26, using pCSN44 as a template. The three PCR fragments, together with the EcoRI/XhoI linearized vector pRS426, were co-transformed into Saccharomyces cerevisiae FY834 (Winston et al. 1995), in which homologous recombination took place. Transformants were selected on SD plates lack- ing uracil. Total DNA from uracil-prototrophic yeast colonies was isolated with the GeneJET plasmid miniprep kit (Fermentas, Vilnius, Lithuania), including an initial step of disrupting yeast cells by the addition of glass beads. The DNA was then used as template to amplify the $d d r 48$ and $b c l g \_12228.1$ replacement construct by use of primers 9 and 12 and 17 and 20, respectively. The complete replacement fragments were used to transform strain B05.10.

For construction of the bcsak1-gfp fusion construct, the homologous recombination system in yeast was also used (Colot et al. 2006). The bcsakl gene was amplified using the primers 27 and 28. These primers contain sequences homologous to the glucanase terminator and the $g f p$ gene, respectively, of the vector pNAH-OGG (Schumacher in press). This vector contains bcniiA-flanks to replace the nitrite reductase-encoding gene of $B$. cinerea, ensuring a defined integration site. Deletion of this gene has no effect on $B$. cinerea, provided nitrogen sources other than nitrate are available (Schumacher in press). The PCR product was co-transformed with pNAH-OGG linearized with NotI into the uracil-auxotrophic strain Saccharomyces cerevisiae FY834, as described above. Plasmidic DNA from uracil-prototrophic yeast colonies was isolated using the SpeedPrep yeast plasmid isolation kit (DualsystemsBiotech, Schlieren, Switzerland) and was transformed into E. coli. Single plasmids were isolated and, after sequencing, the expression cassette was excised, using the enzymes ApaI and SacII, and was transformed into strain $\Delta$ bcsak 1 .

For transformation of B. cinerea, protoplasts were generated using a mixture of glucanex (Novozymes, Bagsværd, Denmark), lysing enzyme (Sigma-Aldrich, St. Louis), and yatalase (Takara Bio Inc., Shiga, Japan). Protoplasts were transformed according to Schulze Gronover and associates (2001), using $20 \mu \mathrm{g}$ of the linearized vector. Resistant colonies were transferred to agar plates containing GB5 agar, supplemented with $70 \mu \mathrm{g}$ of hygromycin B per milliliter (Invitrogen, San Diego, CA, U.S.A.) or $70 \mu \mathrm{g}$ of nourseothricin per milliliter (Werner-Bioagents, Jena, Germany). Single conidial isolates were obtained by spreading conidial suspensions on GB5 plates containing $70 \mu \mathrm{g}$ of hygromycin B per milliliter or $70 \mu \mathrm{g}$ of nourseothricin per milliliter. The conidia were germinated and single colonies were transferred individually to new plates containing the selection marker. Homologous integration of the different transformation constructs was proven by diagnostic PCR and Southern blots.

\section{Standard molecular methods.}

Fungal genomic DNA was isolated as described by Cenis (1992). Southern blot analysis was performed according to Sambrook and associates (1989). Hybridization was carried out in $6 \times \mathrm{SSPE}\left(1 \times \mathrm{SSPE}\right.$ is $0.18 \mathrm{M} \mathrm{NaCl}, 10 \mathrm{mM} \mathrm{NaPO}_{4}$, and $1 \mathrm{mM}$ EDTA [pH 7.7]), $5 \times$ Denhardt's solution, $0.1 \%$ sodium dodecyl sulfate (SDS), and $50 \mathrm{mM}$ phosphate buffer, $\mathrm{pH}$ 6.6, at $65^{\circ} \mathrm{C}$ for 16 to $20 \mathrm{~h}$ in the presence of a random-primed $\left[\alpha-{ }^{32} \mathrm{P}\right] \mathrm{dCTP}$ labeled probe. Filters were washed for $10 \mathrm{~min}$ in $2 \times \mathrm{SSC}(1 \times \mathrm{SSC}$ is $0.15 \mathrm{M} \mathrm{NaCl}$ plus $0.015 \mathrm{M}$ sodium citrate), $0.1 \%$ SDS and for $10 \mathrm{~min}$ in $1 \times \mathrm{SSC}, 0.1 \%$ SDS. Hybridization and washing of the filters were carried out at $65^{\circ} \mathrm{C}$.

For Northern blot analysis RNA was isolated from mycelial samples using the RNAgents total RNA isolation system (Promega, Mannheim, Germany) or the Trizol method (Invitrogen, Carlsbad, CA, U.S.A.). RNA (15- $\mu$ g samples) was transferred to Hybond- $\mathrm{N}^{+}$filters after electrophoresis on a $1 \%$ agarose gel containing formaldehyde, according to Sambrook and associates (1989). Blot hybridizations were carried out in $0.6 \mathrm{M}$ $\mathrm{NaCl}, 0.16 \mathrm{M} \mathrm{Na}_{2} \mathrm{HPO}_{4}, 0.06 \mathrm{M}$ EDTA, 1\% $\mathrm{N}$-lauroylsarcosine (Sigma-Aldrich), $10 \%$ dextran sulfate at $\mathrm{pH} \mathrm{6.2,} \mathrm{as}$ described for Southern blots. 
For quantitative real-time PCR, samples containing $1 \mu \mathrm{g}$ of total RNA were digested with 1 U DNase (Promega) for 30 min and the first-strand cDNA was synthesized using the Superscript II RetroTranscriptase (Invitrogen) according to the manufacturer's instructions. Real-time PCR was carried out using a one-tenth dilution of this cDNA template in an iCycler iQ real-time PCR system (Bio-Rad, Hercules, CA, U.S.A.) with the Bio-Rad iQ SYBR Green supermix. Three different genes were used as reference genes to normalize the cDNA amount in each sample: actin A (primers 29 and 30), elongation factor (primers 31 and 32), and tubulin (primers 33 and 34). The annealing temperature was $54^{\circ} \mathrm{C}$ for $b c b o t 1$ and $b c b o t 4,58^{\circ} \mathrm{C}$ for BC1G_13021.1, BC1G_12856.1, BC1G_ 12146 , and $\mathrm{BC} 1 \mathrm{G} \_09386.1,60^{\circ} \mathrm{C}$ for BC1G_01095.1 and tubulin, and $62^{\circ} \mathrm{C}$ for BC1G_01968.1 and BC $1 \mathrm{G}_{-} 02407.1$. Time extension was $20 \mathrm{~s}$. For each reaction, a pair of primers was designed in such way that one of them hybridized to an exon-exon split to avoid genomic DNA amplification. Therefore, for each gene, the PCR efficiency was between 90 and $110 \%$.

The relative expression of all genes was calculated following the $\Delta \Delta \mathrm{Ct}$ (cycle threshold) method, from the mean of two different determinations of $\mathrm{Ct}$ values.

\section{Macroarray analyses.}

The cDNA macroarrays include $B$. cinerea cDNAs from three different expressed sequence tag (EST) collections. One cDNA library was created from $B$. cinerea TCC 58025 , a nonsporulating overproducer of abscissic acid (ABA) under ABA biosynthesis conditions (Siewers et al. 2004). A second library was derived from a suppression subtractive hybridization approach, used to identify B05.10 genes specifically affected in expression on host plant Phaseolus vulgaris (Schulze Gronover et al. 2004). A third library was derived from germinating conidia of B05.10 and early stages of plant infection (L. Kokkelink, unpublished data). Using the assembly program CAP3 (Huang and Madan 1999), 16,525 cDNA sequences were assembled, resulting in 1,901 contigs and 3,047 singlets. Thus, the macroarrays used in this work contain 4,948 genes, including genes from plant origin. Sequence analysis for prediction of protein function was done using blastX at the National Center for Biotechnology Information (Altschul et al. 1990). Fungal cultivations with the three genotypes (B05.10, $\Delta$ bcsak1, and $\Delta$ bmp3) with and without 10 $\mathrm{mM} \mathrm{H}_{2} \mathrm{O}_{2}$ were repeated three times. The strains were cultivated under standard cultivation conditions in $\mathrm{CD}$ medium with and without $10 \mathrm{mM} \mathrm{H} \mathrm{O}_{2}$. RNA was extracted and used for the production of radioactively labeled cDNA probes for macroarray filter hybridization. Before reverse transcription, $3 \mu \mathrm{g}$ of total RNA was treated with $1 \mathrm{U}$ DNase, following the user's instructions, to eliminate traces of genomic DNA in the sample. To perform RT-PCR, RNA was taken for cDNA synthesis using oligo(dT) ${ }_{12-18}$ primer and SuperScript II reverse transcriptase (Invitrogen) according to the manufacturer's instructions. For the radioactive labeling $\alpha-\left[{ }^{32} \mathrm{P}\right] \mathrm{dCTP}$ was used during the reaction. Each cDNA sample was hybridized once to the macroarrays, making a total of three biological repeats and, due to the two replicates, six values per cDNA clone. The hybridization images from the Typhoon 8600 (GE Healthcare Bio-Sciences AB, Uppsala, Sweden) were analyzed for initial data quantification using ARRAYVISION 8.0 (GE Healthcare Bio-Sciences AB). The Excel macro FiRe (University of Fribourg webpage) was used to select candidate genes for differential expression based upon their fold-change ratios (Beckers and Conrath 2006; Garcion et al. 2006), using standard parameters (lower threshold 0.5 and upper threshold 2.0).

\section{Pathogenicity assays.}

Infection assays were performed with conidia from 10-dayold PDAB agar cultures. Primary leaves of Phaseolus vulgaris L. genotype N90598 (originating from J. D. Kelly, Michigan State University, East Lansing, MI, U.S.A.) were inoculated with $7.5 \mu \mathrm{l}$ of conidial suspensions $\left(2 \times 10^{5}\right.$ conidia $\left.\mathrm{ml}^{-1}\right)$ or with mycelial plugs for the standard pathogenicity test as described by Klimpel and associates (2002). The infected plants were incubated in a plastic propagator box at $20^{\circ} \mathrm{C}$ under natural illumination. Disease symptoms were scored 2 and 3 days postinoculation.

\section{Confocal laser scanning microscopic (CLSM) analyses.}

A glass slide was inoculated with $10 \mu \mathrm{l}$ of a conidial suspension $\left(1 \times 10^{5}\right.$ conidia $\left.\mathrm{ml}^{-1}\right)$ in GB5 medium supplemented with $\left(\mathrm{NH}_{4}\right)_{2} \mathrm{HPO}_{4}(1 \mathrm{mM})$. At $24 \mathrm{~h}$ after inoculation, germinated conidia were analyzed microscopically with an inverted microscope (Leica DMIRE2) equipped with a Leica TCS SP2 laser scanning device (Leica Microsystems, Wetzlar, Germany) using a $63 \times$ water-immersion lens. GFP fluorescence was excited using a 488-nm laser line. Images were collected with a resolution of 8 bits using an emission range between 505 and 550 $\mathrm{nm}$ with a frame average and a line average of 4 . For analysis of the reaction after stress induction, the medium was removed completely and was replaced by medium supplemented with stressors as indicated. If two or more micrographs were compared, exactly the same CLSM settings were used.

\section{Analysis of secondary metabolites.}

${ }^{1} \mathrm{H}$ and ${ }^{13} \mathrm{C}$ nuclear magnetic resonance (NMR) measurements on metabolites isolated from culture extracts were obtained on Varian Unity 400 and Varian Innova 600 NMR spectrometers, with $\mathrm{SiMe}_{4}$ as the internal reference. Mass spectra were recorded on a GC-MS Thermoquest Voyager spectrometer and a VG Autospec-Q spectrometer. High-performance liquid chromatography (HPLC) was performed with a Hitachi/Merck L-6270 apparatus equipped with a UVVIS detector (L 6200) and a differential refractometer detector (RI-71). Thin-layer chromatography was performed on Merck Kiesegel $60 \mathrm{~F}_{254}, 0.2 \mathrm{~mm}$ thick. Silica gel (Merck, Darmstadt, Germany) was used for column chromatography. HPLC purification was accomplished with a silica gel column (Hibar 60, $7 \mathrm{~m}, 1 \mathrm{~cm}$ wide, $25 \mathrm{~cm}$ long). Chemicals were products of Sigma-Aldrich (Buchs SG, Switzerland). All solvents were freshly distilled.

For isolation and characterization of metabolites, the oil extract obtained from both experiments was separated by means of column chromatography on silica gel, with a mixture of ethyl acetate and hexane $(10,20,40,60,80$, and $100 \%$ ethyl acetate) and $20 \%$ methanol in ethyl acetate as solvent.

Extensive spectroscopic analyses by ${ }^{1} \mathrm{H}$ NMR and ${ }^{13} \mathrm{C}$ NMR were used to detect the presence of the various toxins in each fraction. Candidate fractions were further purified by HPLC with an increasing gradient of ethyl acetate to petroleum ether. The toxin structures were analyzed by spectroscopic methods and direct comparison with authentic samples, previously isolated from strains of B. cinerea (Collado et al. 2000, 2007). Semi-preparative HPLC afforded compounds 1 to 10 , from WT and mutants of B. cinerea.

\section{ACKNOWLEDGMENTS}

We thank M. Hahn for providing the $\Delta$ bmp3 strain and L. Kokkelink for sharing unpublished data, B. Oeser for help in bioinformatic analysis, A. Strotbaum and S. Mester for technical assistance, N. Temme for discussions, B. Williamson for critically reading the manuscript, and the Deutsche Forschungsgemeinschaft (DFG project Tu 50-17) for financial support. 


\section{LITERATURE CITED}

Alepuz, P. M., Jovanovic, A., Reiser, V., and Ammerer, G. 2001. Stressinduced MAP kinase $\mathrm{Hog} 1$ is part of transcription activation complexes. Mol Cell. 7:767-777.

Altschul, S. F., Gish, W., Miller, W., Myers, E. W., and Lipman, D. J. 1990. Basic local alignment search tool. J Mol Biol. 215:403-410.

Beckers, G. J. M., and Conrath, U. 2006. Microarray data analysis made easy. Trends Plant Sci. 11:322-323.

Bieszke, J. A., Braun, E. L., Bean, L. E., Kang, S., Natvig, D. O., and Borkovich, K. A. 1999. The nop-1 gene of Neurospora crassa encodes a seven transmembrane helix retinal-binding protein homologous to archaeal rhodopsins. Proc Natl Acad Sci U S A. 96:8034-8039.

Brewster, J. L., De Valoir, T., Dwyer, N. D., Winter, E., and Gustin, M. C. 1993. An osmosensing signal transduction pathway in yeast. Science. 259:1760-1763.

Brito, N., Espino, J. J., and González, C. 2006. The endo- $\beta$-1,4-xylanase $\mathrm{Xyn} 11 \mathrm{~A}$ is required for virulence in Botrytis cinerea. Mol Plant-Microbe Interact. 19:25-32.

Büttner, P., Koch, F., Voigt, K., Quidde, T., Risch, S., Blaich, R., Brückner, B., and Tudzynski, P. 1994. Variations in ploidy among isolates of $\mathrm{Bo}$ trytis cinerea: Implications for genetic and molecular analyses. Curr Genet. 25:445-450.

Cenis, J.L. 1992. Rapid extraction of fungal DNA for PCR amplification. Nucleic Acids Res. 20:2380.

Chen, D., Toone, W. M., Mata, J., Lyne, R., Burns, G., Kivinen, K., Brazma, A., Jones, N., and Bähler, J. 2003. Global transcriptional responses of fission yeast to environmental stress. Mol. Biol. Cell 14:214229.

Chen, D., Wilkinson, C.R.M., Watt, S., Penkett, C.J., Toone, W.M., Jones, N., and Bähler, J. 2008. Multiple pathways differentially regulate global oxidative stress responses in fission yeast. Mol. Biol. Cell 19:308-317.

Christianson, T. W., Sikorski, R. S., Dante, M., Shero, J. H., and Hieter, P. 1992. Multifunctional yeast high-copy-number shuttle vectors. Gene 110:119-122.

Collado, I. G., Aleu, J., Hernández-Galán, R., and Durán-Patrón, R. 2000. Botrytis species an intriguing source of metabolites with a wide range of biological activities. Structure, chemistry and bioactivity of metabolites isolated from Botrytis species. Curr. Org. Chem. 4:1261-1286.

Collado, I. G., Sánchez, A. J. M., and Hanson, J. R. 2007. Fungal terpene metabolites: Biosynthetic relationships and the control of the phytopathogenic fungus Botrytis cinerea. Nat. Prod. Rep. 24:674-686.

Colmenares, A. J., Aleu, J., Duran-Patron, R., Collado, I. G., and HernandezGalan, R. 2002. The putative role of botrydial and related metabolites in the infection mechanism of Botrytis cinerea. J. Chem. Ecol. 28:9971005 .

Colot, H. V., Park, G., Turner, G. E., Ringelberg, C., Crew, C. M., Litvinkova, L., Richard L. Weiss, R. L., Borkovich, K. A., and Dunlap J. C. 2006. A high-throughput gene knockout procedure for Neurospora reveals functions for multiple transcription factors. Proc Natl. Acad. Sci. U.S.A. 103:10352-10357.

Dalmais, B., Schumacher, J., Moraga, J., Le Pecheur, P., Tudzynski, B., Collado, I. G., and Viaud, M. 2011. The Botrytis cinerea phytotoxin botcinic acid requires two polyketide synthases for production and has a redundant role in virulence with botrydial. Mol. Plant Pathol. 12:564579.

Delgado-Jarana, J., Sousa, S., González, F., Rey, M., and Llobell, A. 2006. ThHog1 controls the hyperosmotic stress response in Trichoderma harzianum. Microbiology 152:1687-1700.

de Nadal, E., and Posas, F. 2009. Multilayered control of gene expression by stress-activated protein kinases. EMBO (Eur. Mol. Biol. Organ.) J. 29:4-13.

Dib, L., Hayek, P., Sadek, H., Beyrouthy, B., and Khalaf, R. A. 2008. The Candida albicans Ddr48 protein is essential for filamentation, stress response, and confers partial antifungal drug resistance. Med. Sci. Monitor 14:113-121.

Dixon, K. P., Xu, J., Smirnoff, N., and Talbot, N. J. 1999. Independent signaling pathways regulate cellular turgor during hyperosmotic stress and appressorium-mediated plant infection by Magnaporthe grisea. Plant Cell. 11:2045-2058.

Doehlemann, G., Berndt, P., and Hahn, M. 2006. Different signalling pathways involving a G $\alpha$ protein, cAMP and a MAP kinase control germination of Botrytis cinerea conidia. Mol. Microbiol. 59:821-835.

Du, C., Sarfati, J., Latge, J., and Calderone, R. 2006. The role of the sakA (Hog1) and tcsB (Sln1) genes in the oxidant adaptation of Aspergillus fumigatus. Med. Mycol. 44:211-218.

Dulermo, T., Rascle, C., Billon-Grand, G., Gout, E., Bligny, R., and Cotton, P. 2010. Novel insights into mannitol metabolism in the fungal plant pathogen Botrytis cinerea. Biochem. J. 427:323-332.

Eaton, C. J., Cox, M. P., Ambrose, B., Becker, M., Hesse, U., Schardl, C.
L., and Scott, B. 2010. Disruption of signaling in a fungal-grass symbiosis leads to pathogenesis. Plant Physiol. 153:1780-1794.

Estrada, A. F., and Avalos, J. 2009. Regulation and targeted mutation of opsA, coding for the NOP-1 opsin orthologue in Fusarium fujikuroi. J. Mol. Biol. 387:59-73.

Garcion C., Applimath, F. R. I., and Métraux, J. P. 2006. FiRe and microarrays: A fast answer to burning questions. Trends Plant Sci. 11:320322.

Govrin, E. M., and Levine, A. 2000. The hypersensitive response facilitates plant infection by the necrotrophic pathogen Botrytis cinerea. Curr. Biol. 10:751-757.

Gustin, M. C., Albertyn, J., Alexander, M., and Davenport, K. 1998. Map kinase pathways in the yeast Saccharomyces cerevisiae. Microbiol. Mol. Biol. Rev. 62:1264-1300.

Heller, J., and Tudzynski, P. 2011. Reactive oxygen species in phytopathogenic fungi: Signaling, development, and disease. Annu Rev Phytopathol. 49:369-390.

Huang, X., and Madan, A. 1999. CAP3: A DNA sequence assembly program. Genome Res. 9:868-877.

Idnurm, A., and Howlett, B. J. 2001. Characterization of an opsin gene from the ascomycete Leptosphaeria maculans. Genome. 44:167-171.

Jain, R., Valiante, V., Remme, N., Docimo, T., Heinekamp, T., Hertweck, C., Gershenzon, J., Haas, H., and Brakhage, A. A. 2011. The MAP kinase MpkA controls cell wall integrity, oxidative stress response, gliotoxin production and iron adaptation in Aspergillus fumigatus. Mol Microbiol. 82:39-53.

Kawasaki, L., Sánchez, O., Shiozaki, K., and Aguirre, J. 2002. SakA MAP kinase is involved in stress signal transduction, sexual development and spore viability in Aspergillus nidulans. Mol. Microbiol. 45:1153-1163.

Klimpel, A., Schulze Gronover, C., Williamson, B., Stewart, J. A., and Tudzynski, B. 2002. The adenylate cyclase (BAC) in Botrytis cinerea is required for full pathogenicity. Mol. Plant Pathol. 3:439-450.

Lara-Ortíz, T., Riveros-Rosas, H., and Aguirre, J. 2003. Reactive oxygen species generated by microbial NADPH oxidase NoxA regulate sexual development in Aspergillus nidulans. Mol. Microbiol. 50:1241-1255.

Lara-Rojas, F., Sánchez, O., Kawasaki, L., and Aguirre, J. 2011. Aspergillus nidulans transcription factor AtfA interacts with the MAPK SakA to regulate general stress responses, development and spore functions. Mol. Microbiol. 80:436-454.

Leroch, M., Mernke, D., Koppenhoefer, D., Schneider, P., Mosbach, A., Doehlemann, G., and Hahn, M. 2011. Living Colors in the Gray Mold Pathogen Botrytis cinerea: Codon-Optimized Genes Encoding Green Fluorescent Protein and mCherry, which Exhibit Bright Fluorescence. Appl. Environ. Microbiol. 77:2887-2897.

Liu, W., Leroux, P., and Fillinger, S. 2008. The HOG1-like MAP kinase Sak1 of Botrytis cinerea is negatively regulated by the upstream histidine kinase Bos1 and is not involved in dicarboximide- and phenylpyrrole-resistance. Fungal Genet. Biol. 45:1062-1074.

Liu, W., Soulié, M., Perrino, C., and Fillinger, S. 2011. The osmosensing signal transduction pathway from Botrytis cinerea regulates cell wall integrity and MAP kinase pathways control melanin biosynthesis with influence of light. Fungal Genet. Biol. 48:377-87.

Lyon, G. D., Goodman, B. A., and Williamson, B. 2007. Botrytis cinerea perturbs redox processes as an attack strategy in plants. Pages 119-141 in: Botrytis: Biology, Pathology and Control. Y. Elad, B. Williamson, P. Tudzynski, and N. Delen, eds. Kluwer Academic Publishers, Dordrecht, The Netherlands.

Malonek, S., Rojas, M. C., Hedden, P., Gaskin, P., Hopkins, P., and Tudzynski, B. 2004. The NADPH-cytochrome P450 reductase gene from Gibberella fujikuroi is essential for gibberellin biosynthesis. J. Biol. Chem. 279:25075-25084.

Mas, G., De Nadal, E., Dechant, R., De La Concepción, M. L. R., Logie, C., Jimeno-González, S., 2009. Recruitment of a chromatin remodelling complex by the Hog1 MAP kinase to stress genes. EMBO (Eur. Mol. Biol. Organ.) J. 28:326-336.

McClanahan, T., and McEntee, K. 1986. DNA damage and heat shock dually regulate genes in Saccharomyces cerevisiae. Mol. Cell Biol. 6:90-96.

Michielse, C. B., Becker, M., Heller, J., Moraga, J., Collado, I. G., and Tudzynski, P. 2011. The Botrytis cinerea Reg1 protein, a putative transcriptional regulator, is required for pathogenicity, conidiogenesis and for the production of secondary metabolites. Mol. Plant-Microbe Interact. 24:1074-1085.

Moriwaki, A., Kubo, E., Arase, S., and Kihara, J. 2006. Disruption of SRM1, a mitogen-activated protein kinase gene, affects sensitivity to osmotic and ultraviolet stressors in the phytopathogenic fungus Bipolaris oryzae. FEMS (Fed. Eur. Microbiol. Soc.) Microbiol Lett. 257:253-261.

Pontecorvo, G., Roper, J. A., Chemmons, L. M., Macdonald, K. D., and Bufton, A. W. J. 1953. The genetics of Aspergillus nidulans. Adv. Genet. 5:141-238. 
Proft, M., Mas, G., de Nadal, E., Vendrell, A., Noriega, N., Struhl, K., and Posas, F. 2006. The stress-activated Hogl kinase is a selective transcriptional elongation factor for genes responding to osmotic stress. Mol. Cell. 23:241-250.

Rolke, Y., Liu, S., Quidde, T., Williamson, B., Schouten, A., Weltring, K W., Siewers, V., Tenberge, K. B., Tudzynski, B., and Tudzynski, P. 2004. Functional analysis of $\mathrm{H}_{2} \mathrm{O}_{2}$-generating systems in Botrytis cinerea: The major $\mathrm{Cu}-\mathrm{Zn}$-superoxide dismutase (BcSod1) contributes to virulence on French bean, whereas a glucose oxidase (BcGod1) is dispensable. Mol. Plant Pathol. 5:17-27.

Ruepp, A., Zollner, A., Maier, D., Albermann, K., Hani, J., Mokrejs, M. Tetko, I., Güldener, U., Mannhaupt, G., Münsterkötter, M., and Mewes, H. W. 2004. The FunCat, a functional annotation scheme for systematic classification of proteins from whole genomes. Nucleic Acids Res. 32:5539-5545.

Rui, O., and Hahn, M. 2007. The Slt2-type MAP kinase Bmp3 of Botrytis cinerea is required for normal saprotrophic growth, conidiation, plant surface sensing and host tissue colonization. Mol. Plant Pathol. 8:173184

Sambrook, J., Fritsch, E. F., and Maniatis, T. 1989. Molecular Cloning: A Laboratory Manual. 2nd ed. Cold Spring Harbor Laboratory Press, Cold Spring Harbor, NY, U.S.A.

Sanso, M., Vérgas-Perez, I., García, P., Ayté, J., and Hidalgo, E. 2011. Nuclear roles and regulation of chromatin structure by the stressdependent MAP kinase Sty1 of Schizosaccharomyces pombe. Mol. Microbiol. 82:542-554.

Schaeffer, H. J., and Weber, M. J. 1999. Mitogen-activated protein kinases: Specific messages from ubiquitous messengers. Mol. Cell Biol. 19:2435-2444.

Schouten, A., Tenberge, K. B., Vermeer, J., Stewart, J., Wagemakers, L., Williamson, B., and Van Kan, J. A. L. 2002. Functional analysis of an extracellular catalase of Botrytis cinerea. Mol. Plant Pathol. 3:227-238.

Schulze Gronover, C., Kasulke, D., Tudzynski, P., and Tudzynski, B. 2001. The role of $\mathrm{G}$ protein $\alpha$ subunits in the infection process of the gray mold fungus Botrytis cinerea. Mol. Plant-Microbe Interact. 14:12931302.

Schulze Gronover, C., Schorn, C., and Tudzynski, B. 2004. Identification of Botrytis cinerea genes up-regulated during infection and controlled by the $\mathrm{G} \alpha$ subunit BCG1 using suppression subtractive hybridization (SSH). Mol. Plant-Microbe Interact. 17:537-546.

Schumacher, J. Tools for Botrytis cinerea: New expression vectors make the gray mold fungus more accessible to cell biology approaches. Fungal Genet. Biol. In press.

Segmüller, N., Ellendorf, U., Tudzynski, B., and Tudzynski, P. 2007. BcSak1, a stress-activated mitogen-activated protein kinase, is involved in vegetative differentiation and pathogenicity in Botrytis cinerea. Eukaryot. Cell 6:211-221.

Segmüller, N., Kokkelink, L., Giesbert, S., Odinius, D., Van Kan, J. A. L., and Tudzynski, P. 2008. NADPH oxidases are involved in differentiation and pathogenicity in Botrytis cinerea. Mol. PlantMicrobe Interact. 21:808-819.

Shlezinger, N., Minz, A., Gur, Y., Hatam, I., Dagdas, Y. F., Talbot, N. J., and Sharon, A. 2011. Anti-apoptotic machinery protects the necrotrophic fungus Botrytis cinerea from host-induced apoptotic-like cell death during plant infection. PLoS Pathog. 7:e1002185. Published online.

Siewers, V., Smedsgaard, J., and Tudzynski, P. 2004. The P450 monooxygenase BcABA1 is essential for abscisic acid biosynthesis in Botrytis cinerea. Appl. Environ Microbiol. 70:3868-3876.

Siewers, V., Viaud, M., Jimenez-Teja, D., Collado, I. G., Schulze Gronover, C., Pradier, J. M., Tudzynski, B., and Tudzynski, P. 2005. Functional analysis of the cytochrome P450 monooxygenase gene bcbot1 of Botrytis cinerea indicates that botrydial is a strain-specific virulence factor. Mol. Plant-Microbe Interact. 18:602-612.

Talarczyk, A., and Hennig, J. 2001. Early defence responses in plants infected with pathogenic organisms. Cell. Mol. Biol. Lett. 6:955-970.

Tani, H., Koshino, H., Sakuno, E., and Nakajima, H. 2005. Botcinins A, B, $\mathrm{C}$, and D, metabolites produced by Botrytis cinerea, and their antifungal activity against Magnaporthe grisea, a pathogen of rice blast disease. J. Nat. Prod. 68:1768-1772.

Temme, N., and Tudzynski, P. 2009. Does Botrytis cinerea ignore $\mathrm{H}_{2} \mathrm{O}_{2}$ induced oxidative stress during infection? Characterization of Botrytis activator protein 1. Mol. Plant-Microbe Interact. 22:987-998.

Temme, N., Oeser, B., Massaroli, M., Heller, J., Simon, A., Collado, G. I. Viaud, M., and Tudzynski, P. BcAtf1, a global regulator, controls various differentiation processes and phytotoxin production in Botrytis cinerea. Mol. Plant Pathol. In press.

Tenberge, K. B., Beckedorf, M., Hoppe, B., Schouten, A., Solf, M., and Von Den Driesch, M. 2002. In situ localization of AOS in host-pathogen interactions. Microsc. Microanal. 8:250-251.

Ten Have, A., Mulder, W., Visser, J., and Van Kan, J. A. L. 1998. The endopolygalacturonase gene bcpgl is required to full virulence of Botrytis cinerea. Mol. Plant-Microbe Interact. 11:1009-1016.

Tiedemann, A. V. 1997. Evidence for a primary role of active oxygen species in induction of host cell death during infection of bean leaves with Botrytis cinerea. Physiol. Mol. Plant Pathol. 50:151-166.

Treger, J. M., and McEntee, K. 1990. Structure of the DNA damageinducible gene DDR48 and evidence for its role in mutagenesis in Saccharomyces cerevisiae. Mol. Cell Biol. 10:3174-3184.

Valette-Collet, O., Cimerman, A., Reignault, P., Levis, C., and Boccara, M. 2003. Disruption of Botrytis cinerea pectin methylesterase gene Bcpme1 reduces virulence on several host plants. Mol. Plant-Microbe Interact. 16:360-367.

Viaud, M., Fillinger, S., Liu, W., Polepalli, J. S., Le Pêcheur, P., Kunduru, A. R., Leroux, P., and Legendre, L.2006. A class III histidine kinase acts as a novel virulence factor in Bortrytis cinerea. Mol. Plant-Microbe Interact. 19:1042-1050.

Wilkinson, M. G., Samuels, M., Takeda, T., Toone, W. M., Shieh, J. C. Toda, T., Millar, J. B., and Jones, N. 1996. The Atf1 transcription factor is a target for the Sty1 stress-activated MAP kinase pathway in fission yeast. Genes Dev. 10:2289-2301.

Williamson, B., Tudzynski, B., Tudzynski, P., and Van Kan, J. A. L. 2007. Botrytis cinerea: The cause of grey mould disease. Mol. Plant Pathol. 8:561-580.

Winston, F., Dollard, C., and Ricupero-Hovasse, S. L. 1995. Construction of a set of convenient Saccharomyces cerevisiae strains that are isogenic to S288C. Yeast 11:53-55.

$\mathrm{Xu}$, J. R. 2000. MAP kinases in fungal pathogens. Fungal Genet. Biol. 31:137-152.

Zhang, Y., Lamm, R., Pillonel, C., Lam, S., and Xu, J. R. 2002 Osmoregulation and fungicide resistance: The Neurospora crassa os-2 gene encodes a HOG1 mitogen-activated protein kinase homologue. Appl. Environ. Microbiol. 68:532-538.

Zheng, L., Campbell, M., Murphy, J., Lam, S., and Xu, J. R. 2000. The BMP1 gene is essential for pathogenicity in the gray mold fungus Botrytis cinerea. Mol. Plant-Microbe Interact. 13:724-732.

\section{AUTHOR-RECOMMENDED INTERNET RESOURCE}

University of Fribourg Faculty of Science FiRe and associated macros webpage: www.unifr.ch/plantbio/FiRe/main.html 